\title{
Overexpression of pressure-responsive miRNA-5703 inhibits pressure-induced growth and metastasis of liver cancer
}

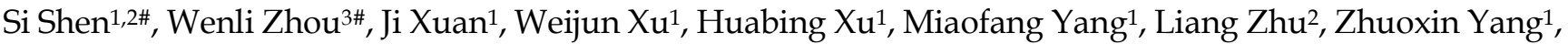 \\ Benzhao Yang ${ }^{4}$, Bin Shi ${ }^{2}$, Ying Zhao ${ }^{5^{*}}$ and Fangyu Wang ${ }^{1 凶 *}$ \\ 1. Jinling Hosp Dept of Gastroenterology and Hepatology, Nanjing Univ, Sch Med, Nanjing 210002, P R China \\ 2. Changzheng Hosp Dept of Gastroenterology, Naval Med Univ, Shanghai 200003, P R China. \\ 3. Changzheng Hosp Dept of Oncology, Naval Med Univ, Shanghai 200003, P R China. \\ 4. Dept of Cardiology, Naval Medical Center, Naval Med Univ, Shanghai 200005, P R China. \\ 5. Changzheng Hosp Dept of Traditional Chinese Medicine, Naval Med Univ, Shanghai 200003, P R China. \\ \#Authors share co-first authorship. \\ *Authors share co-senior authorship. \\ $\triangle$ Corresponding author: Dr. Fangyu Wang, Jinling Hosp Dept of Gastroenterology and Hepatology, Nanjing Univ, Sch Med, Nanjing 210002, P R China. \\ E-mail: wangfy65@nju.edu.cn \\ (c) The author(s). This is an open access article distributed under the terms of the Creative Commons Attribution License (https://creativecommons.org/licenses/by/4.0/). \\ See http://ivyspring.com/terms for full terms and conditions.
}

Received: 2021.07.13; Accepted: 2021.11.07; Published: 2022.01.01

\begin{abstract}
A vast majority of liver cancers coexist with cirrhosis and/or portal hypertension. A high-pressure tumour microenvironment may lead to malignant progression of liver cancer. Through quantitative reverse transcription-polymerase chain reaction, we found that miRNA-5703 was expressed at low levels in HepG2 and Huh-7 cells and pressure-treated $\mathrm{MHCC} 97 \mathrm{H}$ implanted mouse cancer tissues, while its potential target gene, sarcoma gene (SRC), was highly expressed. The expression of miRNA-5703 was higher in liver cancer tissues from Barcelona Clinic Liver Cancer (BCLC) stage Al patients than those from BCLC stage A2-D patients, whereas SRC showed the opposite expression pattern. Bioinformatics analysis, luciferase reporter assay, and western blotting were performed to verify the relationship between miRNA-5703 and its potential target SRC. Using intravital imaging and immunohistochemistry, we demonstrated that pressure promotes tumour growth in subcutaneous tumourigenesis nude mice, and overexpression of miRNA-5703 significantly downregulated $\mathrm{Ki} 67$ and upregulated NM23 in tumour tissues of mice, implying the blockage of tumour growth and metastasis. The activation of proliferation, migration, and invasion of HepG2 and Huh-7 cells by pressure, and inhibition by overexpressing miRNA- 5703 were observed by cell counting kit-8 assay, flow cycle assay, transwell assay, and wound healing assay. After the intervention of pressure, inhibitor, and lentivirus to hepatoma cells, SRC, focal adhesion kinase (FAK), phosphatidylinositol 3-kinase (PI3K), serum/glucocorticoid regulated kinase-3 (SGK3), phosphoinositide dependent protein kinase 1 (PDK1), and paxillin were upregulated, and forkhead box $\mathrm{O} 1$ (FOXO1) and cyclin dependent kinase inhibitor 1B (P27Kipl) were downregulated in pressure-loaded hepatoma cells, which could be reversed by overexpression of miRNA- 5703 or SRC knockdown. In conclusion, upregulation of miRNA-5703 inhibited pressure-induced growth and metastasis by suppressing the SRC-FAK-FOXO1 axis and SRC-paxillin axis. This novel perspective may be conducive to the mechano-inspired anticancer drugs of liver cancer.
\end{abstract}

Key words: liver cancer, portal hypertension, pressure, proliferation, metastasis, miRNA-5703

\section{Introduction}

Liver cancer is currently the third leading cause of cancer-related deaths worldwide [1]. The mortality rate of liver cancer is $8.2 \%$ in both sexes combined [2]. In recent years, immunosuppressants have attracted much attention in the treatment of liver cancer, but compared to other cancers, the response rate of liver cancer is much lower [3]. The tumour microenvironment (TME) is a key interfering factor in 
immunotherapy for liver cancer [4], and the interdependence of biological, chemical, and physical cues affect the TME [5]. However, the role of physical cues in liver cancer has not been definitively elucidated.

Portal hypertension (PHTN) is a recognised risk factor [6] and an independent predictor of liver cancer $[7,8]$. The incidence of liver cancer and mortality due to liver cancer in patients with PHTN is greater than in patients without PHTN [6]. In a median follow-up of 58 months, $12.2 \%$ of patients with cirrhosis and PHTN (without varicose veins) developed liver cancer, and receiver operating characteristic curves identified that those who had a hepatic venous pressure gradient above $10 \mathrm{mmHg}$ had a 6-fold increase in liver cancer incidence [8]. PHTN has also been proven to be a notable risk factor for late recurrence after hepatectomy (hazard ratio: 2.424; confidence interval: 95\%, 1.644-3.574; $\mathrm{P}<0.001$ ) [9]. Recently, an increasing number of investigations using non-invasive examinations, such as computed tomography [10] and spleen stiffness measurement [7], have helped to assess the degree of PHTN and predict the occurrence, development, and recurrence of liver cancer. It has been hypothesised that modifications to the TME associated with PHTN might increase the growth potential of liver cancer and maintain a certain level of resistance to chemoembolisation or promote processes of evasion [6]. PHTN increases the biological pressure in hepatic sinuses [11-13], leading to higher pressure on cancer cells [14], and destroys the mechanical balance of the TME. The mechanism by which pressure regulates the proliferation and metastasis of hepatoma cells remains poorly understood.

Pressure has been shown to be an important factor that influences the growth or aggression of solid tumours [15, 16]. Zeng et al. suggested that pressure activation of malignant colon cells accelerated tumour development [17]. Basson et al. applied increasing pressure between $0-80 \mathrm{mmHg}$ to breast cancer cell lines (MCF-7), prostate cancer cell lines (MLL, PC3), and colon cancer cell lines (SW620, Caco-2, CT-26) for $24 \mathrm{~h}$, and observed that the proliferation of all these pressurised cell lines was stimulated [18]. Goetz et al. found that mechanical transduction, which is dictated by the forces generated by intercellular adhesion, cell contraction, and TME, is a key determinant of tumour progression [19]. Fernnde-zsnchez et al. identified that the mechanical pressure exerted by tumour growth onto non-tumourous adjacent epithelium increased the crypt enlargement accompanying the formation of early tumourous aberrant crypt foci, which suggests that mechanical activation of signalling pathways may function in tumour heterogeneity [20]. However, there have been no reports concerning the function of mechanical pressure in liver cancer.

Previous studies on mechanical-responsive miRNAs have mainly focused on cardiovascular and orthopaedic diseases. Mechanical-sensitive miR-181b$5 p$ expression was suppressed by shear stress, which elevated levels of its target gene STAT, leading to the onset of atherosclerosis [21]. miRNA-181a inhibits inflammatory responses in mice with intervertebral disc degeneration by inhibiting the ERK pathway [22]. Abnormal compressive forces could regulate the expression of miRNA-221, -222, -21 , and -27 in articular cartilage, and the identification of these forces has the potential to improve understanding how they impact tissue homeostasis [23]. Determining whether pressure-responsive miRNAs are involved in the development of liver cancer is is an innovative project worthy of exploration.

Autophosphorylation of SRC (Y418) is an early response to mechanical transduction and leads to the activation of FAK (Y397). This finding suggests that SRC may be a messenger to initiate and spread the growth signal of cells under stress stimulation, and FAK is one of its downstream targets [24]. PI3K catalyzes the phosphorylation of phosphatidylinositol-4,5-diphosphate (PIP2) to phosphatidylinositol3,4,5-triphosphate (PIP3). PIP3 binds to the signal protein PDK1 containing a PH1 hydrophobic structure. PDK1 promotes the phosphorylation of SGK3 T-ring residues in the phosphorylation tank and activates SGK3 [25]. As a gene that inhibits proliferation, FoxO1 phosphorylation is an inactivation process, which promotes cell proliferation. FoxO1 has a positive regulatory effect on P27kip1. P27kip1 is a cell cycle regulator encoded by CDKN1B [26]. For a long time, its function has been related to inhibiting the process of the cell cycle. Under integrin-binding or growth factor stimulation, paxillin is phosphorylated by FAK and Src to create the binding site of binding protein Crk [27]. Paxillin promotes cell adhesion and movement through hyperphosphorylation of casein/serine phosphorylation sites [28]. Depending on the cell environment, these activities may lead to cancer and stimulate cancer progression and metastasis.

In an earlier report [14], we concluded that exerting a pressure of $15 \mathrm{mmHg}$ on liver cancer cell lines (HepG2, Huh-7, and MHCC97H) for $24 \mathrm{~h}$ could promote the proliferation, migration, and invasion of the cells. Under this pressurisation, five pressure-responsive miRNAs and 10,150 mRNAs were screened by miRNA and mRNA microarray, respectively. In this study, we investigated the pathophysiological role and possible mechanism of 
pressure-responsive miRNA-5703 in the growth and metastasis of liver cancer, using in vivo and in vitro experiments, and observed that overexpression of miRNA-5703 may suppress the mechanicaldependent development of liver cancer, which provides a theoretical basis for the combined application of miRNA-5703 overexpression with immunosuppressants.

\section{Materials and Methods}

\section{miRNA and mRNA expression profiling}

The differentially expressed miRNAs and mRNAs screened from the pressurised and unpressurized HepG2 cells are available in the Gene Expression Omnibus (GEO) repository (www.ncbi. nlm.nih.gov/geo/query/acc.cgi?acc $=$ GSE119881 and www.ncbi.nlm.nih.gov/geo/query/acc.cgi?acc $=$ GSE 120194). The Kyoto Encyclopedia of Genes and Genomes (KEGG) database (www.genome.jp/kegg/ annotation) was used for genome/meta genome annotation, and a bubble chart was produced using KOBAS3.0 (Peking University, Beijing, China).

\section{Cell culture and reagents}

The HepG2 cell line was purchased from American Type Culture Collection (HB-8065; ATCC, Manassas, VA, USA). The Huh-7 cell line was purchased from the Japanese Collection of Research Bioresources Cell Bank (0403; JCRB, Manassas, VA, USA). MHCC97H and HL-7702 cell lines were purchased from the Shanghai Cell Bank of the Chinese Academy of Sciences (HB-8065; Shanghai, China). No infection was detected in any of the cells lined by mycoplasma testing. Short tandem repeat analysis was used to authenticate the cell lines. All cells were cultured at $37{ }^{\circ} \mathrm{C}$ under $5 \% \quad \mathrm{CO}_{2}$ in Dulbecco's Modified Eagle's Medium (DMEM; HyClone, Logan, UT, USA) containing 10\% foetal bovine serum (Gibco Life Technologies, Carlsbad, CA, USA), $1 \mathrm{mM}$ sodium pyruvate, $2 \mathrm{mM}$ glutamine, 100 $\mathrm{U} / \mathrm{mL}$ penicillin $\mathrm{G}, 100 \mathrm{mg} / \mathrm{mL}$ streptomycin, and 10 mM HEPES (Sigma, San Francisco, CA, US). Cells were treated with $0.2 \%$ trypsin and $0.02 \%$ EDTA (Thermo Fisher Scientific, Waltham, MA, USA) when collected for experiments.

\section{Pressure loading}

The 2-dimensional (2D) pressure loading system was designed and manufactured by our research group, and the protocol can be found in our previous papers [14, 29, 30]. The Flexcell-5000 Compression System (Flexcell International Corp, Burlington, NC, US) was used to exert pressure on the 3D cultured cells. The methods of cell 3D culture and pressure loading have been described in our previous paper
[14].

\section{Cell Counting Kit-8 assay}

A Cell Counting Kit-8 (CCK-8) assay was conducted using a kit (Dojindo Laboratories, Kumamoto, Japan) to detect cell proliferation, and the protocol used has been detailed in our previous paper [14].

\section{Cell cycle analysis by flow cytometry}

A cell cycle assay kit (MULTI SCIENCES, Hangzhou, Zhejiang, China) was used to detect the cell cycle, and the details of the methods have been reported in our previous paper [14].

\section{Transwell assay}

Transwell ${ }^{\circledR}$ Permeable Supports consisting of Snapwell ${ }^{\mathrm{TM}}$ and Netwell ${ }^{\mathrm{TM}}$ inserts (Corning, Corelle, NY, US) were used to perform the cell invasion assay, and the protocol used was the same as that used in our previous paper [14].

\section{Wound healing assay}

Here, $5 \times 10^{5}$ pre-treated cells were seeded into each well of a 24-well plate (Corning, Corelle, New York, USA), and the details of the methods have been reported in our previous paper [14].

\section{Immunofluorescence staining}

A cover slide was placed in each well of a 6-well plate (Corning, Corelle, New York, USA) and $7 \times 10^{4}$ cells were added per well for overnight cultivation. Subsequently, after fixing with $4 \%$ paraformaldehyde (Sinopharm Chemical Reagent Co. Ltd., Shanghai, China) for $30 \mathrm{~min}$, the cells were blocked with 3\% bovine serum albumin (BSA) for $30 \mathrm{~min}$ after membrane permeabilisation. They were then incubated with a 1:300 dilution of primary antibodies overnight at $4{ }^{\circ} \mathrm{C}$. Then, a 1:300 dilution of secondary antibodies were added and incubated for $1 \mathrm{~h}$. DAPI (G1012, Servicebio, Wuhan, China) was used to stain nuclei. The stained cells were observed and photographed using a fluorescence microscope (DMi8, Leica, Wetzlar, Germany) after being sealed with a sealing reagent that inhibited fluorescence quenching.

\section{Cytoskeleton staining}

For cytoskeleton staining, a cover slide was placed in each well of a 6-well plate and $7 \times 10^{4}$ cells were added per well for overnight cultivation. The next day, the culture medium was discarded and the cells on the climbing slides were washed thrice with phosphate-buffered saline (PBS; HyClone, Logan, UT, US) for 5 min each. Then, $1 \mathrm{~mL} 4 \%$ paraformaldehyde (Sinopharm Chemical Reagent Co. Ltd., Shanghai, 
China) was added to the pores to fix the cells for 30 $\mathrm{min}$. The cells were then washed thrice with PBS for 5 min each. The cells were stained with $80 \mathrm{~mL} \mathrm{1:300}$ phalloidin (Servicebio, Wuhan, China) at room temperature $\left(25^{\circ} \mathrm{C}\right)$ for $2 \mathrm{~h}$. The cells were then washed with PBS thrice for 5 min each. Finally, $500 \mu \mathrm{L}$ DAPI was used to stain the nuclei for $15 \mathrm{~min}$. The staining solution was discarded and the cells were washed thrice with PBS for $5 \mathrm{~min}$ each. The slides were observed and photographed using a fluorescence microscope (DMi8, Leica, Wetzlar, Germany) after being sealed with a sealing reagent to inhibit fluorescence quenching.

\section{Dual-Luciferase reporter gene assay}

HEK293T cells were co-transfected with pMIR-Report-SRC 3'-UTR (wild-type or mutant), miR-5703 mimic, or the control. The cells were harvested $24 \mathrm{~h}$ later, and a luciferase assay was performed using the Dual-Luciferase Reporter Assay System (E1910, Promega, WI, US) according to the manufacturer's instructions. Luciferase activity was expressed as a percentage of that of the control. The universal sequencing forward and reverse primers of H11164 and H11165 vectors (OBIO, Shanghai, China) were Luc-C-F (5'-GAGGAGTTGTGTTTGTGGAC-3') and M13F (5'- TGTAAAACGACGGCCAGT-3'). The binding site was a 7 mer-m8 which was predicted from TargetScan website (http://www.targetscan.org/ vert_71/).

\section{Western blotting}

Cells were lysed in RIPA lysis buffer (Servicebio, Wuhan, China). The lysates were centrifuged at $16099.2 \times g$ for $10 \mathrm{~min}$, and the protein concentrations were measured by the standard BCA assay (Pierce ${ }^{\mathrm{TM}}$ BCA Protein Assay Kit, New York, USA) according to the manufacturer's instructions. Equal amounts of protein were separated using a PAGE Gel Fast Preparation Kit (Beyotime Biotechnology, Shanghai, China) according to the manufacturer's instructions. The membranes were then blocked in PBST containing $3 \%$ BSA for $1 \mathrm{~h}$ at room temperature. Then, they were probed with primary antibody at $4{ }^{\circ} \mathrm{C}$ overnight and incubated with the secondary antibody for $1 \mathrm{~h}$ at room temperature. The protein bands were detected using the ECL western blotting Detection Reagent (Pierce, New York, USA). The film was exposed at various times depending on the antibody.

\section{RNA extraction and quantitative reverse transcription PCR}

mRNA levels and miRNA levels were quantified by reverse transcription PCR (RT-qPCR) as previously described [14]. The primers (wcgene Biotech, Shanghai, China) used in this study are listed in Table
1 and 2. Glyceraldehyde 3-phosphate dehydrogenase (GAPDH) and U6 were used as controls for mRNA and miRNA detection, respectively. Relative gene expression was calculated using the $2^{-\Delta \Delta \mathrm{Cq}}$ method [31] after normalisation to the expression of GAPDH or U6 small nuclear RNA, and the results were statistically analysed as mean \pm standard deviation (SD).

Table 1. Primer sequences of miRNA-5703 used for reverse transcription-quantitative polymerase chain reaction.

Gene name $\quad$ Forward primer sequence

hsa-miR-5703 5'-AGGAGAAGTCGGGAAGGT-3'

Table 2. Primer sequences of mRNAs used for reverse transcription-quantitative PCR.

\begin{tabular}{|c|c|c|}
\hline $\begin{array}{l}\text { Gene } \\
\text { name }\end{array}$ & Forward primer & Reve \\
\hline PTK2 & $\begin{array}{l}\text { 5'-GCTTACCTTGACCCCAACTT } \\
\text { G-3' }\end{array}$ & $\begin{array}{l}\text { 5'-ACGTTCCATACCAGTACCCAG- } \\
3^{\prime}\end{array}$ \\
\hline PIK3R1 & $\begin{array}{l}\text { 5'-AGCATTGGGACCTCACATTA } \\
\text { CACA-3' }\end{array}$ & $\begin{array}{l}\text { 5'-ACTGGAAACACAGTCCATGCA } \\
\text { CATA-3' }\end{array}$ \\
\hline SRC & $\begin{array}{l}\text { 5'-GACAGGCTACATCCCCAGC-3 } \\
\text { 1 }\end{array}$ & $\begin{array}{l}\text { 5'-CGTCTGGTGATCTTGCCAAAA- } \\
3^{\prime}\end{array}$ \\
\hline SGK3 & $\begin{array}{l}\text { 5'-ACAGTCCAAAACACCAGTCA } \\
\text { G-3 }\end{array}$ & $\begin{array}{l}\text { 5'-TCTGTGAGGTAGAGTGTAGCT } \\
\text { TC-3' }\end{array}$ \\
\hline FOXO1 & $\begin{array}{l}\text { 5'-TGATAACTGGAGTACATTTC } \\
\text { GCC-3' }\end{array}$ & $\begin{array}{l}\text { 5'-CGGTCATAATGGGTGAGAGTC } \\
\text { T-3' }\end{array}$ \\
\hline $\begin{array}{l}\text { CDKN } \\
1 B\end{array}$ & $\begin{array}{l}\text { 5'-ATCACAAACCCCTAGAGGGC } \\
\text { A - } 3^{\prime}\end{array}$ & $\begin{array}{l}\text { 5'-GGGTCTGTAGTAGAACTCGGG } \\
-3^{\prime}\end{array}$ \\
\hline PDPK1 & $\begin{array}{l}\text { 5'-TTCCGAGCTGGAAACGAGTA } \\
\text { T-3' }\end{array}$ & $\begin{array}{l}\text { 5'-GGTCTCTTGCCTTAGGGAAGA } \\
\text { A-3' }\end{array}$ \\
\hline
\end{tabular}

\section{Cell adhesion assay}

Matrigel (Corning, Corelle, New York, USA) and serum-free DMEM medium (HyClone, Logan, UT, USA) were mixed to form a basement membrane of 10 $\mu \mathrm{g} / \mathrm{mL}$. Six 96-well plates (Corning, Corelle, New York, USA) were laid with $60 \mu \mathrm{L} /$ well of the basement membrane, and the plates were placed in an ultra-clean cabinet for $24 \mathrm{~h}$. Then, serum-free DMEM was added to the wells. After $1 \mathrm{~h}$, the matrix adhesive Matrigel was washed away. HepG2, Huh-7, and MHCC97H cells were inoculated into six 96-well plates at a density of 4,000 cells/well. For each cell line, one plate was cultured under environmental pressure, and the other plate was pressurised to 15 $\mathrm{mmHg}$ for culture. After $24 \mathrm{~h}$, the medium was discarded, and the cells were washed thrice with PBS (HyClone, Logan, UT, US). The cells were fixed with $100 \mu \mathrm{L}$ methanol (Aladdin, Shanghai, China) for 15 min and then the methanol was discarded. Then, 100 $\mu \mathrm{L}$ of hoe33258 dye solution (Beyotime Biotechnology, Shanghai, China) was added, incubated for $15 \mathrm{~min}$, and washed out with $\mathrm{H}_{2} \mathrm{O}_{2}$ (Aladdin, Shanghai, China). The number of cells was recorded and photographed using a fluorescence microscope (CX31; Olympus Corporation, Tokyo, Japan). 


\section{Plasmid construction and lentivirus packaging}

The overexpressed miRNA-5703 plasmid and sarcoma gene (SRC) intervention plasmid used for lentivirus packaging were constructed by Shanghai Collariaceae Biology (Shanghai, China). Based on the principle of base complementary pairing, three interfering target sequences were designed (5'-GAC AGACCTGTCCTTCAAGAA-3'; 5'-GCTCGGCTCATT GAAGACAAT-3'; 5'-GGCTCCAGATTGTCAACA ACA-3') and primers were synthesised. The primers were annealed and ligated into a pLenR-GPH interference vector (Zorin, Shanghai, China). The plasmid was digested with restriction enzymes to ensure the correct size of the cleaved band. Dh5a competent cells were used to transform the interference plasmid and amplify it in bacteria. The plasmid was then extracted and sequenced.

\section{Tumour formation in nude mice}

Twenty-four nude mice were divided into four groups, each group treated with subcutaneous injections under the armpit as follows: 1) $200 \mu \mathrm{L}$ MHCC $97 \mathrm{H}$ cells with a density of $1 \times 10^{7}$ cells $/ \mathrm{mL} ; 2$ ) $200 \mu \mathrm{L}$ of MHCC97H cells at a density of $1 \times 10^{7}$ cells/mL under $15 \mathrm{mmHg}$ of pressure for $24 \mathrm{~h}$; 3) 200 $\mu \mathrm{L}$ of MHCC97H cells (with empty virus vector) at a density of $1 \times 10^{7}$ cells $/ \mathrm{mL}$ under $15 \mathrm{mmHg}$ of pressure for $24 \mathrm{~h}$; and 4) $200 \mu \mathrm{L}$ of MHCC97H cells with miRNA-5703 overexpression infected by lentivirus at a density of $1 \times 10^{7}$ cells $/ \mathrm{mL}$ under 15 $\mathrm{mmHg}$ of pressure for $24 \mathrm{~h}$. All nude mice were weighed before MHCC97H cell inoculation. The vital signs of nude mice were monitored during the experiment, and in vivo imaging was performed on day 10 after cell inoculation.

\section{Immunohistochemistry}

Tissue sections were rehydrated, immersed in $0.3 \% \mathrm{dH}_{2} \mathrm{O}$, and then treated with citrate buffer (10 $\mathrm{mM}, \mathrm{pH}$ 6.0). Next, the sections were treated with primary antibodies as follows: Ki67 (1:200 dilution, Abcam, Shanghai, China) and NM23 (1:500 dilution, Abcam, Shanghai, China) overnight at $4{ }^{\circ} \mathrm{C}$, followed by incubation with secondary antibodies for $20 \mathrm{~min}$ at room temperature. Sections were visualised with diaminobenzidine, diaminobenzidine substrate, and haematoxylin counterstain. Images were acquired with a Leica microscope (DMi8, Leica, Wetzlar, Germany) at $\times 400$ magnification.

\section{Hematoxylin-eosin staining}

Liver tissues were fixed in $4 \%$ paraformaldehyde solution for $24 \mathrm{~h}$. The dehydration process was conducted with the conventional gradient alcohol for 1 min each time, followed by two 5 min washes with xylene, wax dipping, paraffin embedding, and slicing (4 $\mu \mathrm{m}$ slices). Paraffin slices were routinely dewaxed in water and cleaned with xylene for 5 min thrice, with $100 \%$ ethanol for 10 min twice, and twice with $95 \%$ ethanol for $10 \mathrm{~min}$. Next, they were washed twice in $\mathrm{dH}_{2} \mathrm{O}$ for $5 \mathrm{~min}$. The sections were stained with haematoxylin for $10 \mathrm{~min}$. The slices were cleaned with $\mathrm{dH}_{2} \mathrm{O}$ and then differentiated with $1 \%$ hydrochloric acid alcohol for $5 \mathrm{~s}$. After cleaning with $\mathrm{dH}_{2} \mathrm{O}$, the slices were treated with ammonia water and stained with eosin solution for $3 \mathrm{~min}$. The tissues were dehydrated with 95\% ethanol twice for $5 \mathrm{~min}$, and then they were placed in xylene twice for $5 \mathrm{~min}$. The slides were then removed and dried. Finally, they were sealed with neutral gum, and the histopathological changes of the liver tissues were observed under an optical microscope (CX31, Olympus Corporation, Tokyo, Japan).

\section{Statistical analyses}

Results were compared using Student's t-test, and the data are expressed as means \pm SD of at least three independent experiments. All $\mathrm{P}$ values were calculated using two-tailed tests, obtained using the SPSS software (version 16.0; SPSS, Chicago, IL). Statistical significance was set at $\mathrm{P}<0.05$.

\section{Results}

\section{Prediction of pressure-induced signalling pathways}

Using three target gene prediction websites (MicroDB, MicroTarBase and TargetScan), the target genes of five pressure-sensitive miRNAs (miRNA5703, miRNA-630, miRNA-7641, miRNA-7-5p, and miRNA-4485-3p) [14] identified by miRNA microarray were predicted. MicroDB predicted 1,213 target genes, TargetScan predicted 10,679 target genes, and MicroTarBase predicted 1,222 target genes (Fig. 1A). Combined, 11,526 genes were obtained. Of the 11,526 predicted target genes, 1,309 corresponded to differentially expressed mRNAs, which were identified by an mRNA microarray (Fig. 1B). The SRC gene was found amongst the differentially expressed predicted target genes.

KEGG pathway analysis of the 1,309 target genes revealed the relative materiality of the pathways of which the top three cancer growth and metastasis-related pathways were the focal adhesion (FA) pathway, the PI3K pathway, and the FOXO pathway (Fig. 1C). By investigating the KEGG pathway maps, we found that the conjoint upstream gene of the three pathways was SRC, which is also one of the predicted target genes of downregulated miRNA-5703 under pressure loading. 
A

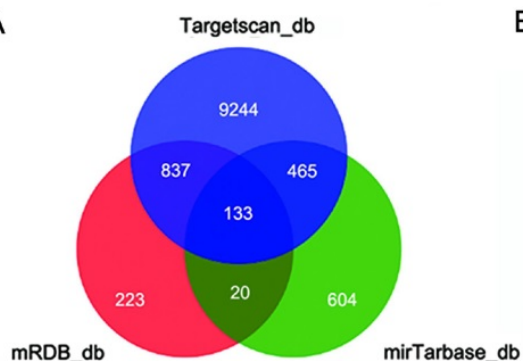

B

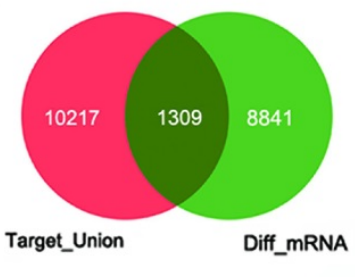

D

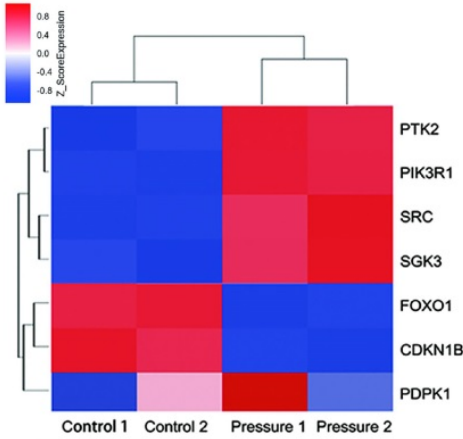

E

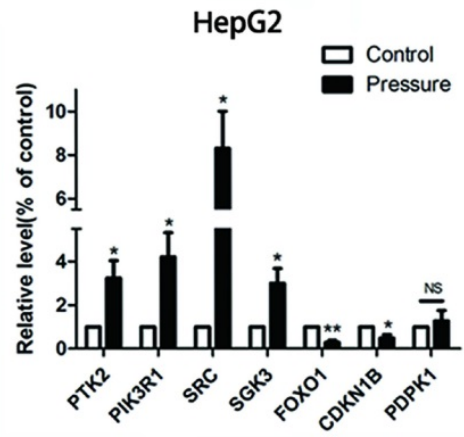

Huh-7

$\square$ Control

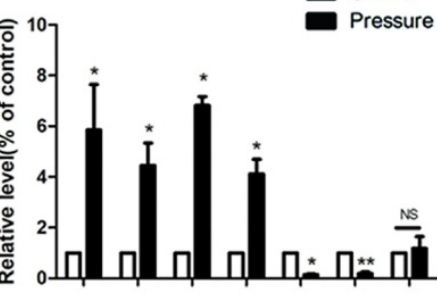

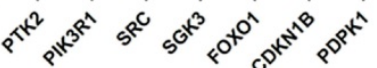

$\mathrm{F}$

G

\begin{tabular}{|l|l|}
\hline SystematicName & A_23_P308603 \\
\hline $\mathrm{P}$ & 0.003864811 \\
\hline FC (abs) & 0.683283137 \\
\hline Regulation & DOWN \\
\hline Case1 & 5.555450196 \\
\hline Case2 & 5.484358156 \\
\hline Case3 & 5.607873632 \\
\hline Control1 & 6.072126534 \\
\hline Control2 & 5.880991274 \\
\hline Control3 & 6.067442877 \\
\hline SystematicName & hsa-miRNA-5703 \\
\hline
\end{tabular}

\begin{tabular}{|l|l|}
\hline ProbeName & A_23_P308603 \\
\hline$P$ & 0.003864811 \\
\hline FC (abs) & 8.866895 \\
\hline Regulation & UP \\
\hline 1.txt:gProcessedSignal(normalized) & 8.124106 \\
\hline 2.txt:gProcessedSignal(normalized) & 8.197108 \\
\hline 3.txt:gProcessedSignal(normalized) & 11.11616 \\
\hline 4.txt:gProcessedSignal(normalized) & 11.501913 \\
\hline GeneSymbol & SRC \\
\hline Description & $\begin{array}{l}\text { Homo sapiens SRC proto-oncogene, } \\
\text { non-receptor tyrosine kinase (SRC), transcript } \\
\text { variant 1, mRNA [NM_005417] }\end{array}$ \\
\hline
\end{tabular}

Figure 1. Prediction of pressure-induced signaling pathways. (A) The predicted overlapping target genes of differentially expressed microRNAs, identified by microarray, using three publicly available bioinformatics algorithms (TargetScan, miRDB, and miRTarBase). (B) The predicted target genes of the differentially expressed microRNA identified by microRNA microarray were combined and ones that corresponded with differentially expressed mRNAs were identified by mRNA microarray, and 1,309 predicted target genes were obtained. (C) KEGG pathway analysis was conducted on the 1,309 mRNAs, and bubble diagrams were obtained to predict pressure-induced signaling pathways. (D) The expression of genes associated with cancer-associated pressure-inducible pathways were verified by mRNA microarray. (E) The expressions of genes associated with cancer-associated pressure-inducible pathways were verified by RT-qPCR. (F) The table shows the result of the miRNA microarray with miRNA-5703. (G) The table shows the result of the mRNA microarray with SRC. NS indicates the means are not significantly different $(P>0.05)$, mean $\pm S D, n=3$. A two-tailed Student's t-test was used. **P $<0.01$, $* \mathrm{P}<0.05$.

An mRNA microarray was used to detect changes in HepG2 cells cultured for $24 \mathrm{~h}$ (control group) and cells under $15 \mathrm{mmHg}$ of pressure for $24 \mathrm{~h}$ (pressure-treated group). A cluster heat map of differentially expressed genes screened by microarray which correlated to the above three pathways is shown in Fig. 1D. Among them, protein tyrosine kinase-2 (PTK2), phosphatidylinositol 3-kinase (PI3K, PIK3R1), SRC, and serum/glucocorticoid regulated kinase-3 (SGK3) were upregulated in pressurised liver 
cancer cells; forkhead box O1 (FOXO1) and cyclin dependent kinase inhibitor 1 B (CDKN1B, P27Kip1) were downregulated; phosphoinositide dependent protein kinase 1 (PDK1) showed no statistically significant changes in expression. We verified the expression of these genes in HepG2 and Huh-7 cell lines by RT-qPCR (Fig. 1E, P $<0.05$, or $\mathrm{P}<0.01$ ).

\section{Verification of SRC as a target of miRNA-5703}

The expression of miRNA-5703 and SRC detected by miRNA array and mRNA microarray are shown in Fig. 1F and 1G, respectively. The expression of miRNA-5703 in pressurised HepG2 cells was downregulated by approximately 0.68 times to that in the cells of control group (Fig. 1F), and the expression of SRC was upregulated by approximately 8.87 times to that in the cells of control group (Fig. 1G). We then verified the microarray results in three liver cancer cell lines (HepG2, Huh-7, and MHCC97H) by RT-qPCR (Fig. 2A, P $<0.05, \mathrm{P}<0.01$, or $\mathrm{P}<0.001$ and 2B, $\mathrm{P}<0.05$ ), and the results were consistent with those of the microarray. In addition, there was no significant change in their expression in the normal liver cell line HL-7702 (Fig. 2A, P > 0.05, and 2B, P > $0.05)$.
A

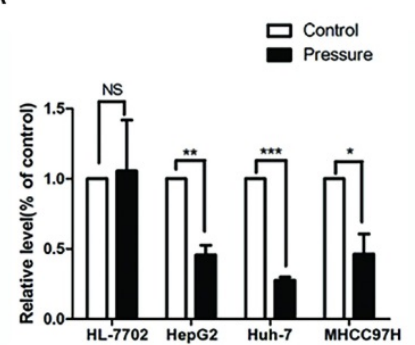

C
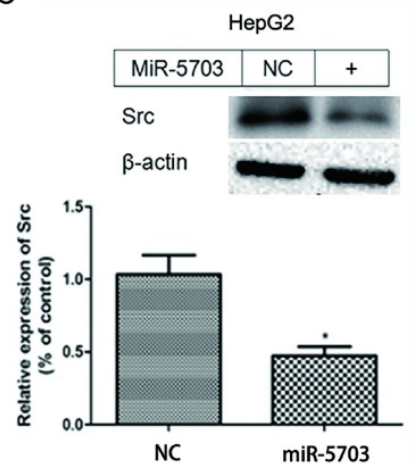

G
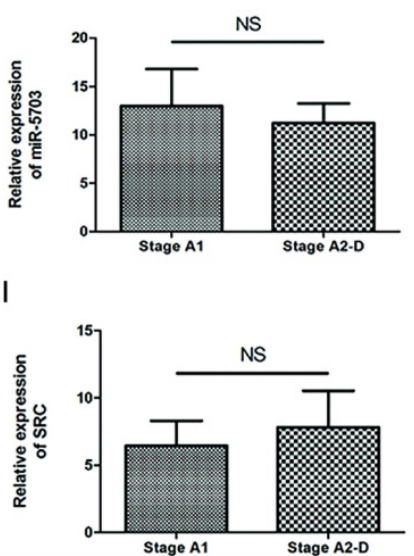

B

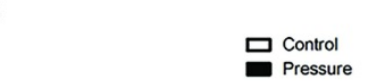

$\mathrm{E}$

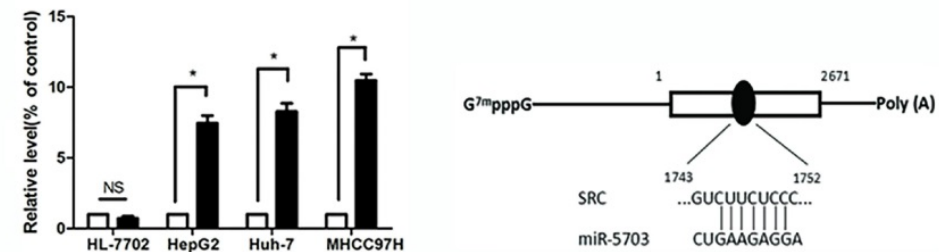

$\mathrm{F}$

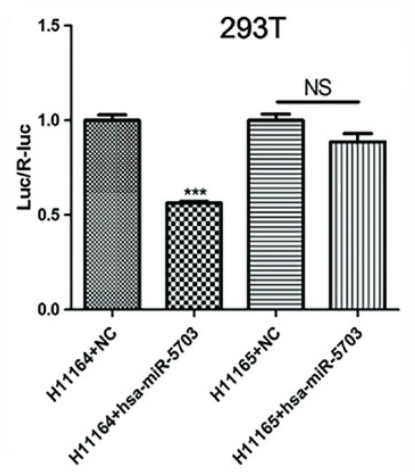

$\mathrm{K}$

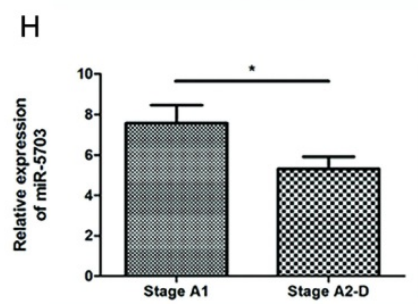

$\mathrm{J}$

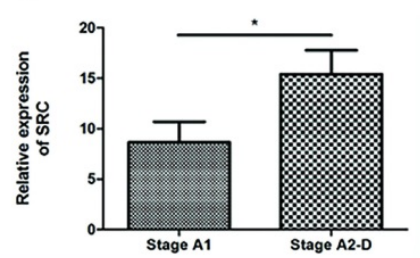

SRC in HCC tissues vs adjacent none tumoral liver 100 tissues of patients classified to BCLC Stage A1

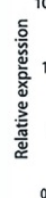
tissues of patients classified to BCLC Stage A2 to D

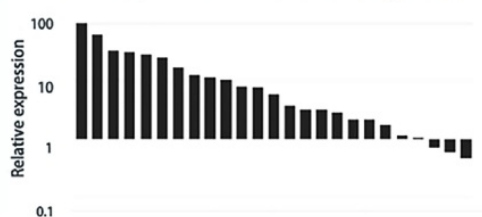

L SRC in HCC tissues vs adjacent none tumoral liver

Figure 2. Verification of SRC as a target of miRNA-5703. (A) RT-qPCR analysis demonstrated that pressure inhibited the expression of miRNA-5703 in different malignant hepatoma cell lines, but had no effect on the normal liver cell line. (B) RT-qPCR analysis demonstrated that pressure promoted the expression of SRC in different malignant hepatoma cell lines, but had no effect on the normal liver cell line. (C) In HepG2 and (D) Huh-7 cells SRC mRNA levels were negatively regulated by overexpression of miRNA-5703. $\beta$-actin is shown as a loading control. (E) The binding site of miRNA-5703 in the 3'-UTR of the SRC gene was predicted by TargetScan. (F) Luciferase reporter assays were performed in HEK293T cells cotransfected with SRC with the wild-type 3'-UTR(h1 164) or mutated 3'-UTR(h1 165) and miRNA-5703 mimics or microRNA negative control (NC). (G) The expression of miR-5703 in liver cancer tissues from patients in stage A2-D was suppressed relative to the expression in tissues from patients in stage A1, (H) while a difiference in expression was not observed between the adjacent normal tissues of patients in the two stages. (I) The mRNA levels of SRC in liver cancer tissues from patients in stage A2-D was higher than that in tissues from patients in stage Al (J) while a difiference in expression was not observed between in the adjacent normal tissues of patients in the two stages. (K) and (L) The higher expression of SRC in HCC tissues was observed by RT-qPCR analysis. NS indicates the means are not significantly different (P $>0.05)$, mean $\pm S D, n=3$. A two-tailed Student's t-test was used. $* * * P<0.001$, *** $<0.01, * P<0.05$. 
Western blotting showed that SRC expression was inhibited in both HepG2 and Huh-7 cells after miRNA-5703 overexpression (Fig. 2C and 2D, P < 0.05). The miRNA-5703 binding site was predicted using the TargetScan website (Fig. 2E), and it was a 7mer-m8 positioned at nucleotides $1,745-1,751$ of the SRC 3\$-UTR. Wild-type plasmids and plasmids with a mutated binding site were transfected into HEK293T cells. The light signals produced by the luciferase of firefly and produced by the luciferase of sea kidney were detected, and their ratios were calculated. The ratio decreased by $43.69 \%$ after overexpression of miRNA-5703 with the wild-type binding site in SRC (Fig. 2F, P < 0.001), while there was no significant difference in the ratio before and after overexpression of miRNA-5703 after binding site mutation (Fig. 2F, P $>0.05$ ).

Twenty-two cases of liver cancer tissues and adjacent normal tissues (more than $5 \mathrm{~cm}$ away from cancer tissues) were collected from patients with liver cancer that were classified as BCLC stage A1 (without PHTN). Twenty-five cases of liver cancer tissues and adjacent normal tissues were collected from patients with liver cancer that were classified as stage A2-D (with PHTN). The expression of miR-5703 in liver cancer tissues from patients in stage A2-D was suppressed relative to that of tissues from patients in stage A1 (Fig. 2G, $\mathrm{P}<0.05$ ), but not in the adjacent normal tissues (Fig. 2H, P > 0.05). The mRNA levels of $\mathrm{SRC}$ in liver cancer tissues from patients in stage A2-D was higher than that of tissues from patients in stage A1 (Fig. 2I, $\mathrm{P}<0.05$ ), but not in the adjacent normal tissues (Fig. 2J, $\mathrm{P}>0.05$ ). In the 22 paired tissues of patients in stage A1, 19 (86.4\%) showed higher SRC expression in liver cancer tissues than in adjacent normal tissues, of which $12(63.1 \%)$ highly expressed SRC ( $>2$ times) and 7 (36.8\%) did not have as high expression levels ( $<2$ times; Fig. 2K). In 25 paired tissues of patients in stage A2-D, the expression of SRC in $22(88 \%)$ of liver cancer tissues was higher than that in adjacent normal tissues, of which 19 pairs (86.3\%) highly expressed SRC (> 2 times), while 3 pairs $(15.7 \%)$ did not have as high expression levels $(<$ 2 times; Fig. 2L).

\section{Overexpression of miRNA-5703 inhibits pressure-induced proliferation of hepatoma cells}

Flow cytometry was used to detect proliferation of the HepG2 and Huh-7 cell lines. As shown in Fig. 3A, overexpression of miRNA-5703 significantly inhibited the proportion of HepG2 and Huh-7 cells in the $S$ phase $(P<0.01)$, and knocking down SRC had similar effects $(P<0.01)$. The HepG2 and Huh-7 cell lines were categorized into four groups based on the experimental conditions: control (conventional culture), pressure (culture under $15 \mathrm{mmHg}$ of pressure), pressure + miRNA-5703 $(+)$ (culture under $15 \mathrm{mmHg}$ of pressure with over-expression of miRNA-5703), and pressure + SRC (-) (culture under $15 \mathrm{mmHg}$ of pressure after knocking down SRC). The CCK-8 assay was used to detect the proliferation of the liver cancer cells (Fig. 3B, $\mathrm{P}<0.05, \mathrm{P}<0.01$ ). The results showed that overexpression of miRNA-5703 significantly inhibited the proliferation of HepG2 and Huh-7 cells, and knocking down SRC achieved similar results. The CCK-8 assay showed that there was no effect on the growth of pressure-loaded HL-7702 cells (Fig. 3C, P > 0.05).

\section{Overexpression of miRNA-5703 inhibits pressure-induced cell proliferation via SRC-FAK--FOXO 1 pathway}

Using western blotting, we found that $15 \mathrm{mmHg}$ pressure loading promoted the expression of SRC, FAK, PI3K, and SGK3, and inhibited the expression of FOXO1 and P27Kip1 (Fig. 4A and 4B), which was consistent with the results of the microarray illustrated in Fig. 1D. Meanwhile, the expression of phosphorylated SRC (pSRC; Y418), pFAK (Y397), pPDK1 (S241), and pSGK3 (T320) were upregulated, which indicated that pressure not only increased the transcription of SRC, FAK, PIK3R1, and SGK3 at the mRNA level, but also activated the phosphorylation of these proteins. It should be noted that the expression of PDK1 at the mRNA level is not regulated by pressure, but pressure can promote phosphorylation of PDK1 at the protein level. Pressure loaded cells were treated with Herbimycin A (pSRC inhibitor), Gsk2256098 (pFAK inhibitor), LY294002 (PI3K inhibitor), PHT-427 (PDK1 inhibitor) and EMD638683 (SGK3 inhibitor; Fig. 4A and 4B), and the relationship between upstream and downstream proteins in the cascade reaction was detected and the results of the grey analysis are shown as histogram in Fig. S1 (HepG2) and Fig. S2 (Huh-7).

Overexpression of miRNA-5703 or SRC knockdown inhibited the expression of downstream proteins, which suggests a mechanism by which miRNA-5703 inhibits tumour growth. (Fig. 5, $\mathrm{P}<0.05$, $\mathrm{P}<0.01$ or $\mathrm{P}<0.01$ ).

\section{Overexpression of miRNA-5703 inhibits pressure-induced migration and invasion of hepatoma cells}

HepG2 and Huh-7 cell lines were divided into four groups based on experimental conditions: control (conventional culture), pressure $(15 \mathrm{mmHg}, 24 \mathrm{~h})$, pressure + miRNA-5703 (+) $(15 \mathrm{mmHg}, 24 \mathrm{~h} \mathrm{+}$ miRNA-5703 over-expression), and pressure + SRC (-) 
(15 mmHg, $24 \mathrm{~h}+$ SRC knockdown). Using a cell scratch assay, we showed that both overexpression of miRNA-5703 and SRC knockdown inhibited the migration of HepG2 and Huh-7 cells. (Fig. 6A, P < $0.05, \mathrm{P}<0.01$ or $\mathrm{P}<0.001)$. A transwell assay showed that overexpression of miRNA-5703 significantly inhibited the invasion of HepG2 and Huh-7 cells, and SRC knockdown had a similar effect on the proliferation of the hepatoma cells (Fig. 6B, $\mathrm{P}<0.05$, or $\mathrm{P}<0.01$ ). However, pressure had no significant effect on the migration of HL-7702, as assessed by the

A

Control
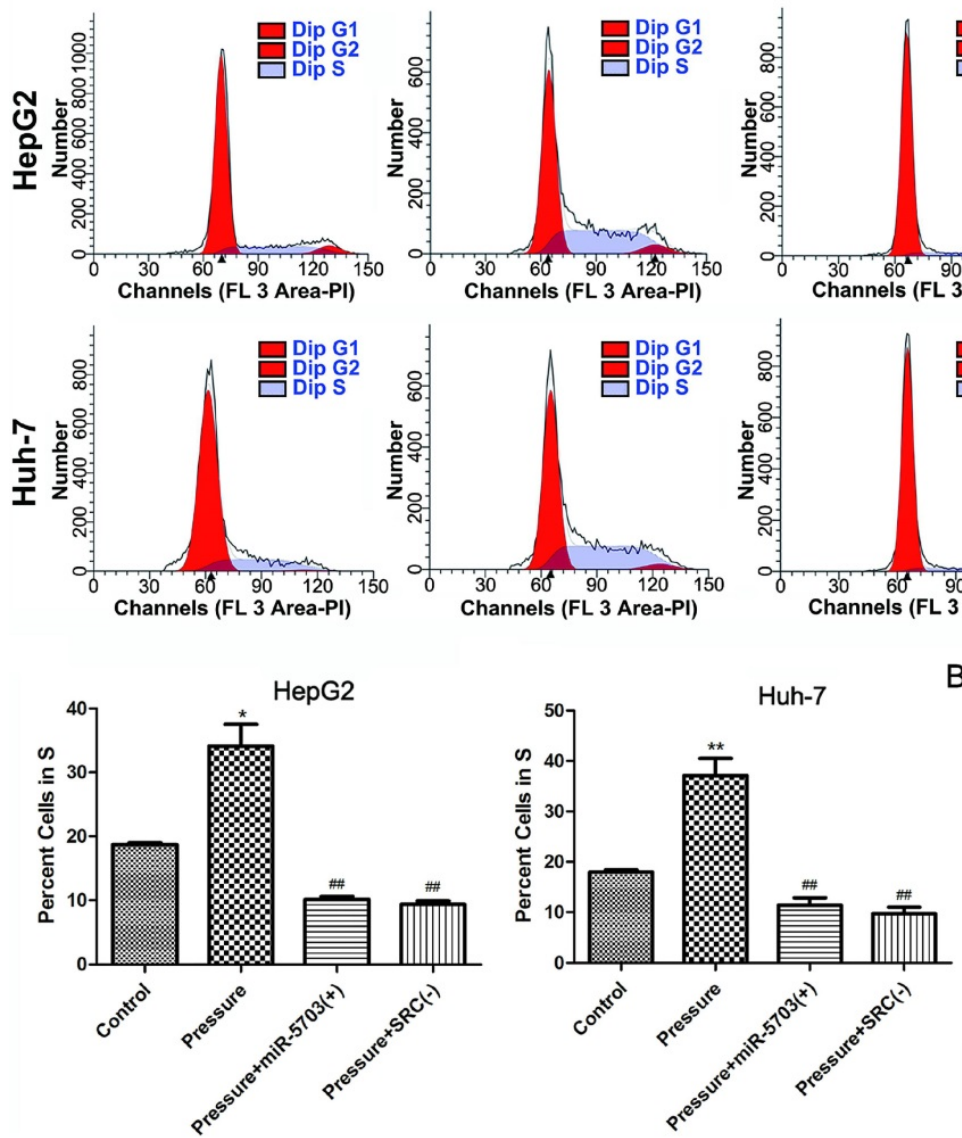

C

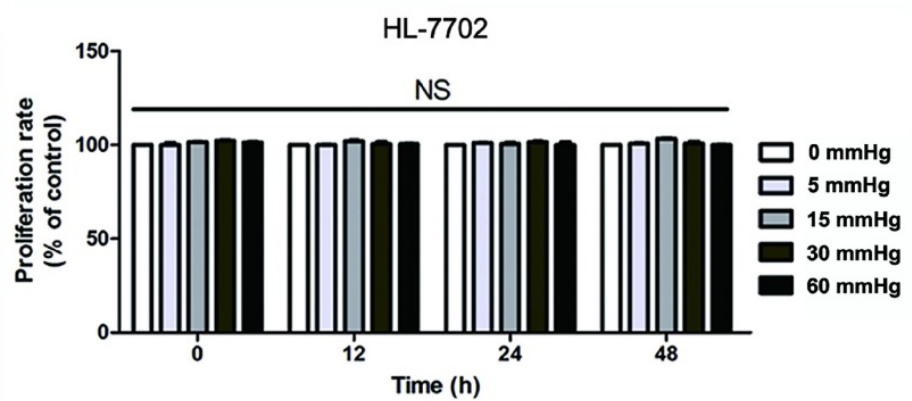

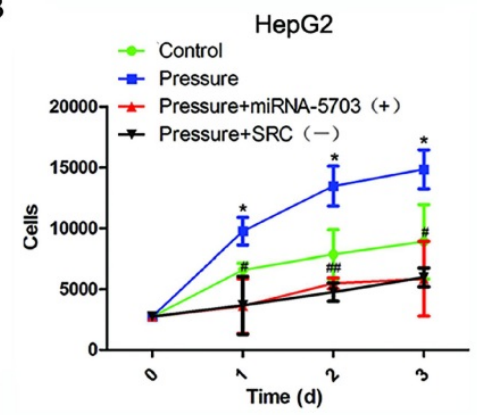

transwell assay (Fig. 6C, P > 0.05)

The peripheral membrane protein GM130, which is strongly attached to the Golgi membrane, is involved in controlling cell polarisation and directed cell migration [32]. The expression of GM130 was also increased in the HepG2, Huh-7, and HL-7702 cells, which was detected by an immunofluorescence assay (Fig. 7A). The cell adhesion assay showed that the number of HepG2, Huh-7, and MHCC97H cell lines adhering to the matrix was significantly increased after pressure loading (Fig. 7B).

\section{Pressure+miR-5703(+) Pressure+SRC(-)}
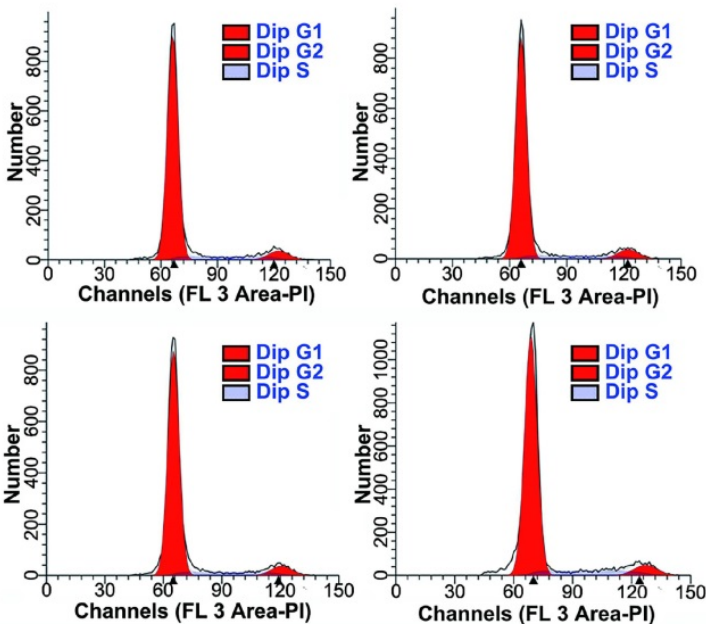

HepG2

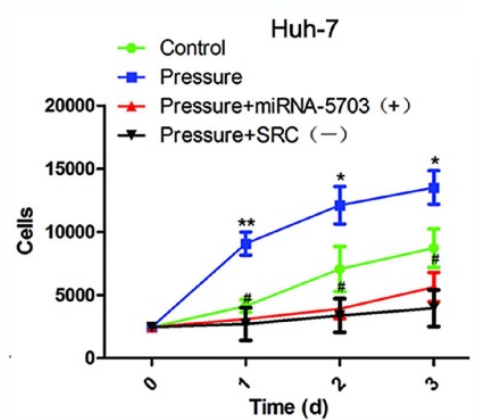

Figure 3. Overexpression of miRNA-5703 inhibited pressure-induced proliferation of hepatoma cells. (A) Overexpression of miRNA-5703 and SRC silencing reduced the number of cells in S phase, which was assessed by flow cytometry analysis. (B) Overexpression of miRNA-5703 and SRC gene silencing inhibited pressure-induced hepatoma cell proliferation, which was assessed by CCK-8 assay. (C) CCK-8 assay was used to detect the proliferation of normal hepatocyte HL-7702 under different pressure loading conditions, and no significant difference was found. NS indicates the means are not significantly different $(P>0.05)$, mean $\pm S D, n=3$. A two-tailed Student's t-test was used vs Control: ***P $<0.001, * * \mathrm{P}<0.01, * \mathrm{P}<0.05 ;$ Vs Pressure: $\# \mathrm{P}<0.01$, \#P $<0.05$ 
A

\begin{tabular}{|l|c|c|c|c|c|c|c|c|}
\hline & $0 \mathrm{mmHg}$ & \multicolumn{7}{|c|}{$15 \mathrm{mmHg}$} \\
\hline DMSO & - & - & + & + & + & + & + & + \\
\hline Herbimycin A & - & - & - & + & - & - & - & - \\
\hline GSK225698 & - & - & - & - & + & - & - & - \\
\hline LY294002 & - & - & - & - & - & + & - & - \\
\hline PH-427 & - & - & - & - & - & - & + & - \\
\hline GSK650394 & - & - & - & - & - & - & - & + \\
\hline
\end{tabular}

pSRC

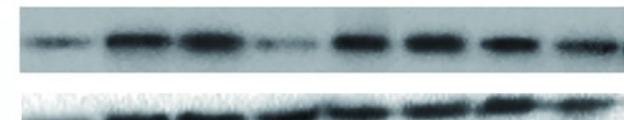

SRC

pFAK

FAK

pPDK1

PDK1

pSGK3

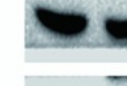

SGK3

FOX01

$\mathrm{P} 27^{\mathrm{Kip} 1}$

Cyclin D1

$\beta$-actin
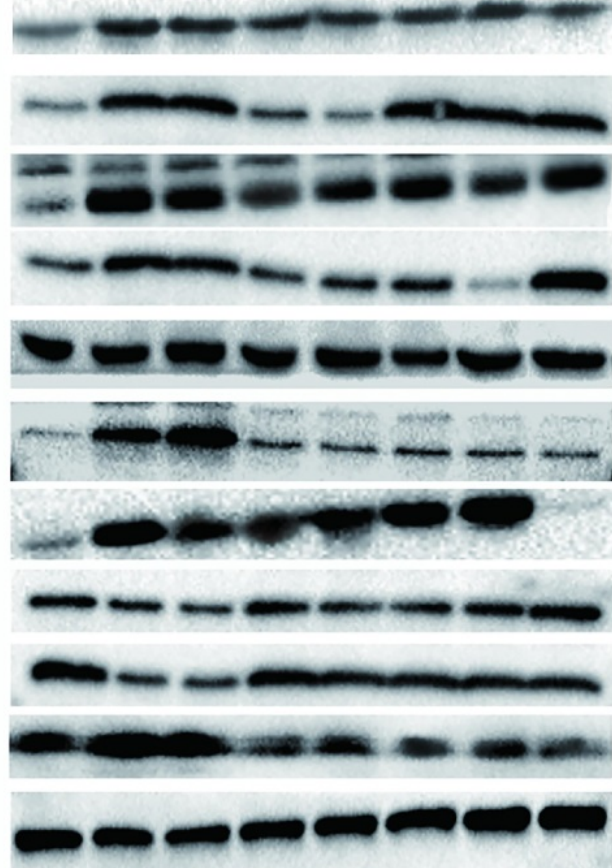
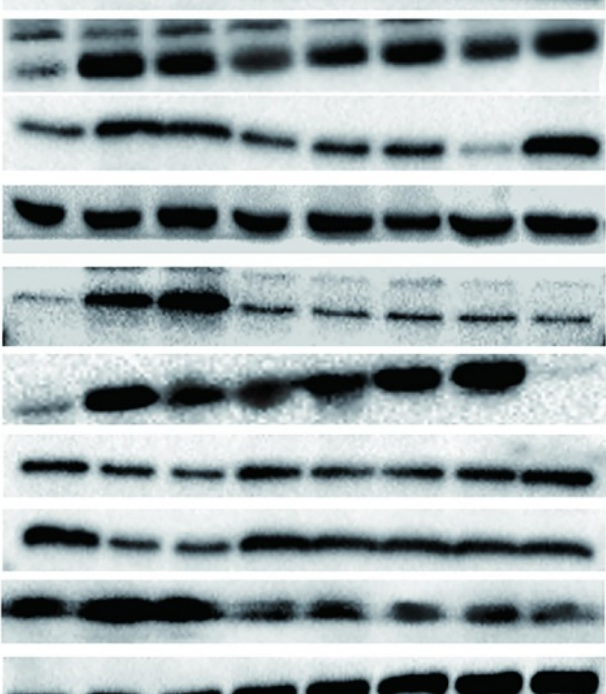

B

\begin{tabular}{|l|c|c|c|c|c|c|c|c|}
\hline & $0 \mathrm{mmHg}$ & \multicolumn{7}{|c|}{$15 \mathrm{mmHg}$} \\
\hline DMSO & - & - & + & + & + & + & + & + \\
\hline Herbimycin A & - & - & - & + & - & - & - & - \\
\hline GSK225698 & - & - & - & - & + & - & - & - \\
\hline LY294002 & - & - & - & - & - & + & - & - \\
\hline PH-427 & - & - & - & - & - & - & + & - \\
\hline GSK650394 & - & - & - & - & - & - & - & + \\
\hline
\end{tabular}
pSRC

SRC

pFAK

FAK

pPDK1

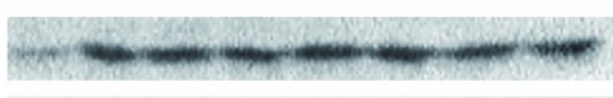

PDK1

pSGK3

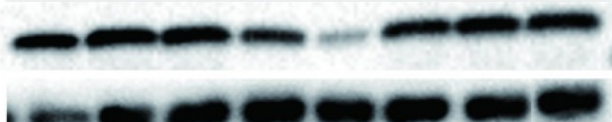

SGK3

FOXO1

$\mathrm{P} 27^{\mathrm{Kip1}}$

Cyclin D1

$\beta$-actin
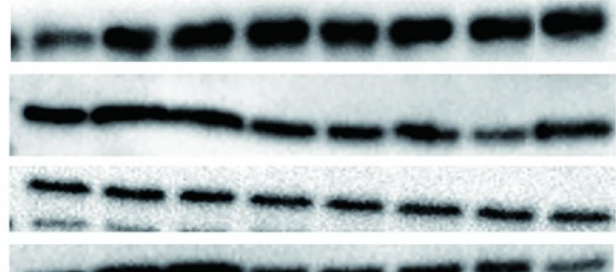

(2)
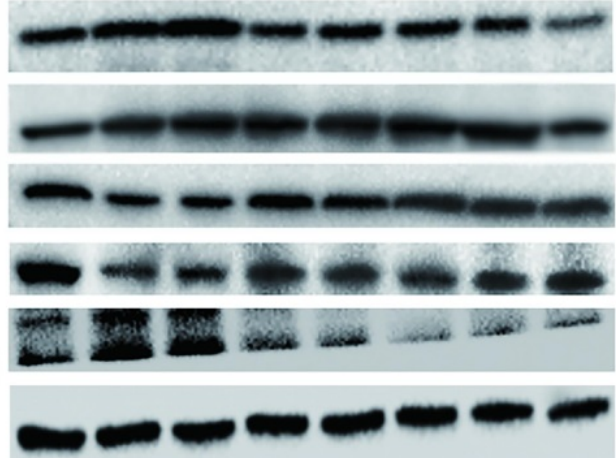

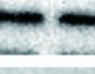

Figure 4. Pressure induced cell proliferation via the SRC-FAK-FOXO1 pathway. Upregulations of SRC, FAK, PI3K, SGK3, and PDK1, and downregulation of FOXO1 and P27Kipl in pressure loaded cells were observed by western blotting. The upstream and downstream interaction relationship and sequence of proteins in the cascade reaction were explored through the application of inhibitors. The relationship between the inhibitors and their target proteins are as follows: Herbimycin A-SRC (Y418); LY294002-PI3K; GSK2256098-FAK (Y397); PHT-427-PDK1 (S241); EMD638683-SGK3 (T320).

The actin microfilaments of HepG2 and Huh-7 cells were stained with the ghost pencil-ring peptide. The results showed that pressure increased the number of cytoskeleton microfilaments, while overexpression of miRNA-5703 significantly reduced it (Fig. 8A, $\mathrm{P}<0.05, \mathrm{P}<0.01, \mathrm{P}<0.001$, or $\mathrm{P}>0.05$ ). Immunofluorescence showed that the expression of FA protein vinculin was upregulated by pressure, while overexpression of miRNA-5703 significantly inhibited the expression of vinculin in cells under pressure (Fig. 8B, $\mathrm{P}<0.05, \mathrm{P}<0.01$, or $\mathrm{P}>0.05$ ).

\section{Overexpression of miRNA-5703 inhibits pressure-induced cell migration and invasion via the SRC-paxillin pathway}

Under $15 \mathrm{mmHg}$ of pressure, herbimycin A and GSK2256098 inhibited paxillin expression $(\mathrm{P}<0.05)$, while LY294002, PHT-427, and EMD638683 had no significant effect on paxillin expression. This indicated that $15 \mathrm{mmHg}$ pressure loading promoted the expression of SRC and FAK in HepG2 and Huh-7 cells, and it remarkably upregulated the expression of paxillin (Fig. 9A, $\mathrm{P}<0.05$, or $\mathrm{P}<0.01$ ). Overexpression of miRNA-5703 or knockdown of SRC inhibited the expression of paxillin, which suggests that this may be the mechanism by which miRNA-5703 in inhibits tumour metastasis (Fig. 9B, $\mathrm{P}<0.05$, or $\mathrm{P}<0.01$ ).

The MHCC97H cells were divided into four groups based on experimental conditions: control (conventional culture), pressure $(15 \mathrm{mmHg}, 24 \mathrm{~h})$, pressure + vector $(15 \mathrm{mmHg}, 24 \mathrm{~h}+$ vector $)$, and pressure + miRNA-5703 (+) (15 mmHg, $24 \mathrm{~h}+$ miRNA-5703 over-expression). The cells were injected subcutaneously into mice and imaged in vivo $10 \mathrm{~d}$ post-injection. We found that tumour size and weight increased in the pressure loaded cell group, but decreased in the miRNA-5703 overexpression group (Fig. 10A, $\mathrm{P}<0.05, \mathrm{P}<0.001$, or $\mathrm{P}>0.05$ ). Hematoxylin-eosin (HE) staining of liver cancer and normal liver tissue is shown in Fig. 10B. The results of the western blot suggested that pressure-upregulated SRC was suppressed in the miRNA-5703 overexpression group (Fig. 10C, $\mathrm{P}<0.05, \mathrm{P}<0.01$, or $\mathrm{P}$ $>0.05)$. 
A

\begin{tabular}{|l|c|c|c|c|}
\hline Pressure & + & + & + & + \\
\hline MiR-5703 & NC & NC & + & + \\
\hline SRC & NC' & - & NC' & - \\
\hline
\end{tabular}

pFAK

FAK

pPDK1

PDK1

pSGK3

SGK3

FOXO1

P27Kip1

Cyclin D1

$\beta$-actin
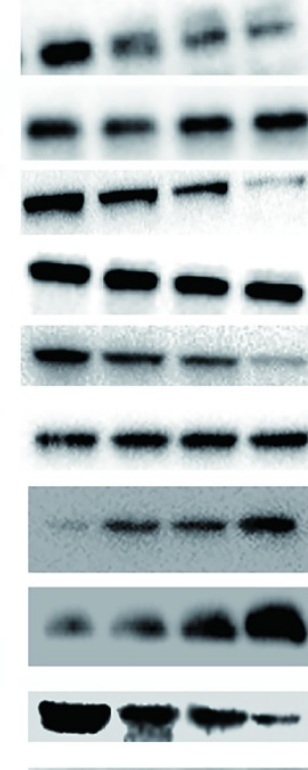

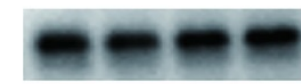

Pressure+NC+NC

100 Pressure+miR-5703 (+)+NC

口 Pressure+NC+SRC (-)

血 Pressure+miR-5703 (+)+SRC (-)

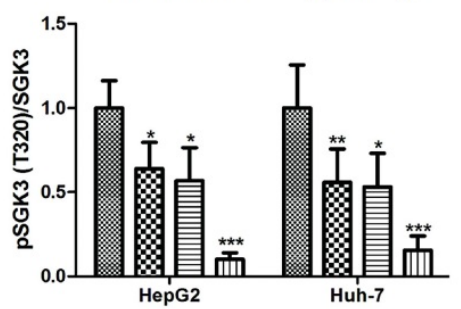

\begin{tabular}{|l|c|c|c|c|}
\hline Pressure & + & + & + & + \\
\hline MiR-5703 & NC & NC & + & + \\
\hline SRC & NC' & - & NC' & - \\
\hline
\end{tabular}

pFAK

FAK

pPDK1
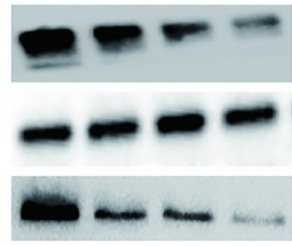

PDK1

pSGK3

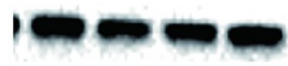

pSGK3

SGK3
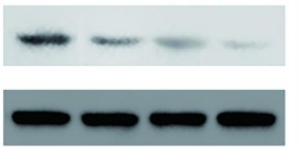

FOXO1

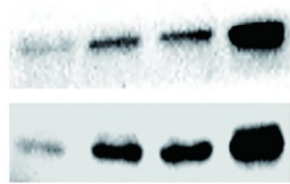

P27Kip1

Cyclin D1

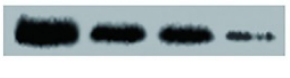

$\beta$-actin

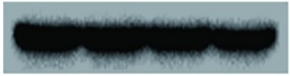

$$
\begin{aligned}
& \text { Pressure+NC+NC' } \\
& \text { Pressure+miR-5703(+)+NC' } \\
& \text { 旦 Pressure+NC+SRC (-) } \\
& \text { 罗 Pressure+miR-5703 (+)+SRC (-) }
\end{aligned}
$$

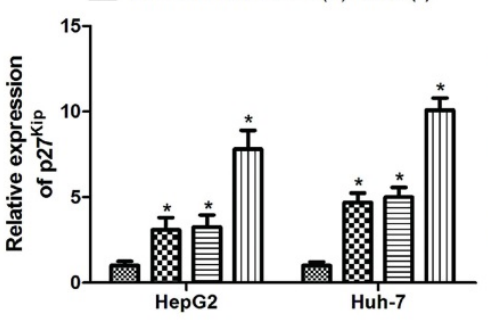

B
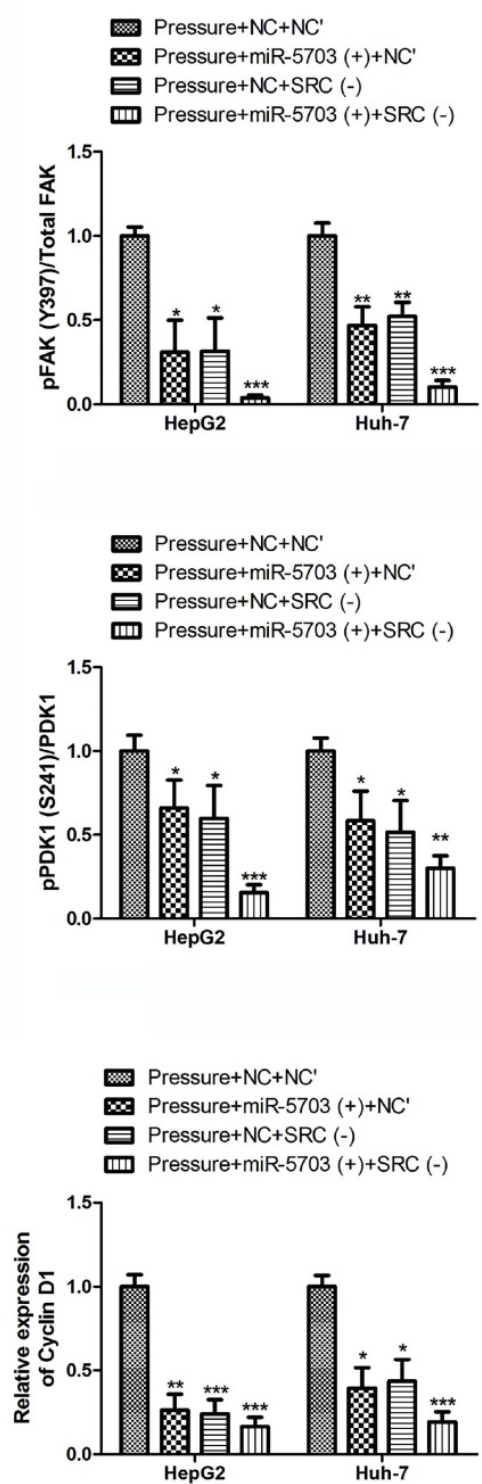

Figure 5. Overexpression of miRNA-5703 and SRC gene silencing reversed the proliferative effects induced by pressure loading in the indicated cells. (A) The expression of proteins in the SRC-FAK-FOXO1 pathway were detected by western blotting in HepG2 (left) and Huh-7 (right). $\beta$-actin was used as a loading control. (B) Using grey analysis, the ratio of phosphorylated protein to total protein was calculated and is displayed in a histogram, and the expression differences between the groups are shown. Mean \pm SD, $\mathrm{n}$ = 3. A two-tailed Student's t-test was used. ${ }^{* * * *} \mathrm{P}<0.001,{ }^{* *} \mathrm{P}<0.01,{ }^{*} \mathrm{P}<0.05$.

The immunohistochemical assay showed that the expression of Ki67 was upregulated in tumours in the pressurised group and downregulated significantly in tumours in the miRNA-5703 overexpression group, and the expression of NM23 had the opposite pattern (Fig. 10D, $\mathrm{P}<0.05$, or $\mathrm{P}>$ 0.05). Ki67 is an indispensable antigen in cell proliferation and is associated with mitosis. In clinical practice, Ki67 is used to label cells in the proliferation cycle [33]. NM23 is highly expressed in well-differentiated tumours, and it inhibits tumour cell metastasis. It is also negatively correlated with lymph node metastasis. In the clinic, the detection of NM23 gene expression by immunohistochemistry is an important method for judging the metastatic ability of tumours [34]. The expression of miRNA-5703 in tumours of the four groups was assessed by RT-qPCR (Fig. 10E, P $<0.05, \mathrm{P}<0.001$, or $P>0.05)$. The schematic diagram of cascade reaction is shown in Fig. 11.

\section{Discussion}

In recent years, mechano-inspired anticancer drugs that target components of transduction and mechanosensitive signalling pathways have emerged. Etaracizumab, Volociximab, and Cilengitide are undergoing clinical trials and are aimed at preventing the pro-metastatic signalling transduction associated with integrin-mediated sensing of various mechanical cues in the TME [16]. Changes in the liver mechanical 
microenvironment caused by cirrhosis and PHTN may be involved in the regulation of liver cancer growth and metastasis. However, to date, there has been no research on a drug that targets the mechanical environment of liver cancer which is continuously enveloped by stiff matrix TME and hypertension from the portal system. Our findings suggest that miRNA intervention may prevent tumor promotion from stiffness of the extracellular matrix and suppress the development of liver cancer. These findings provide novel information that can potentially be utilized for the development of new drugs.

A
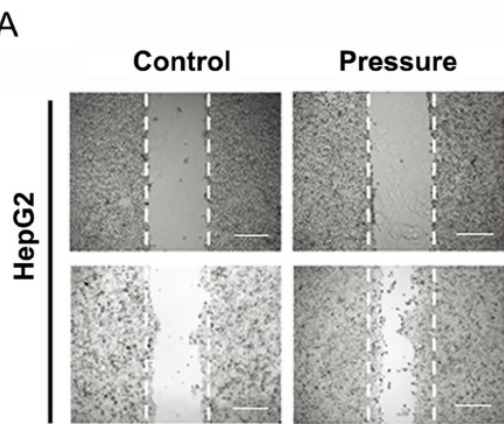
Pressure
+ miR-5703 $(+)$
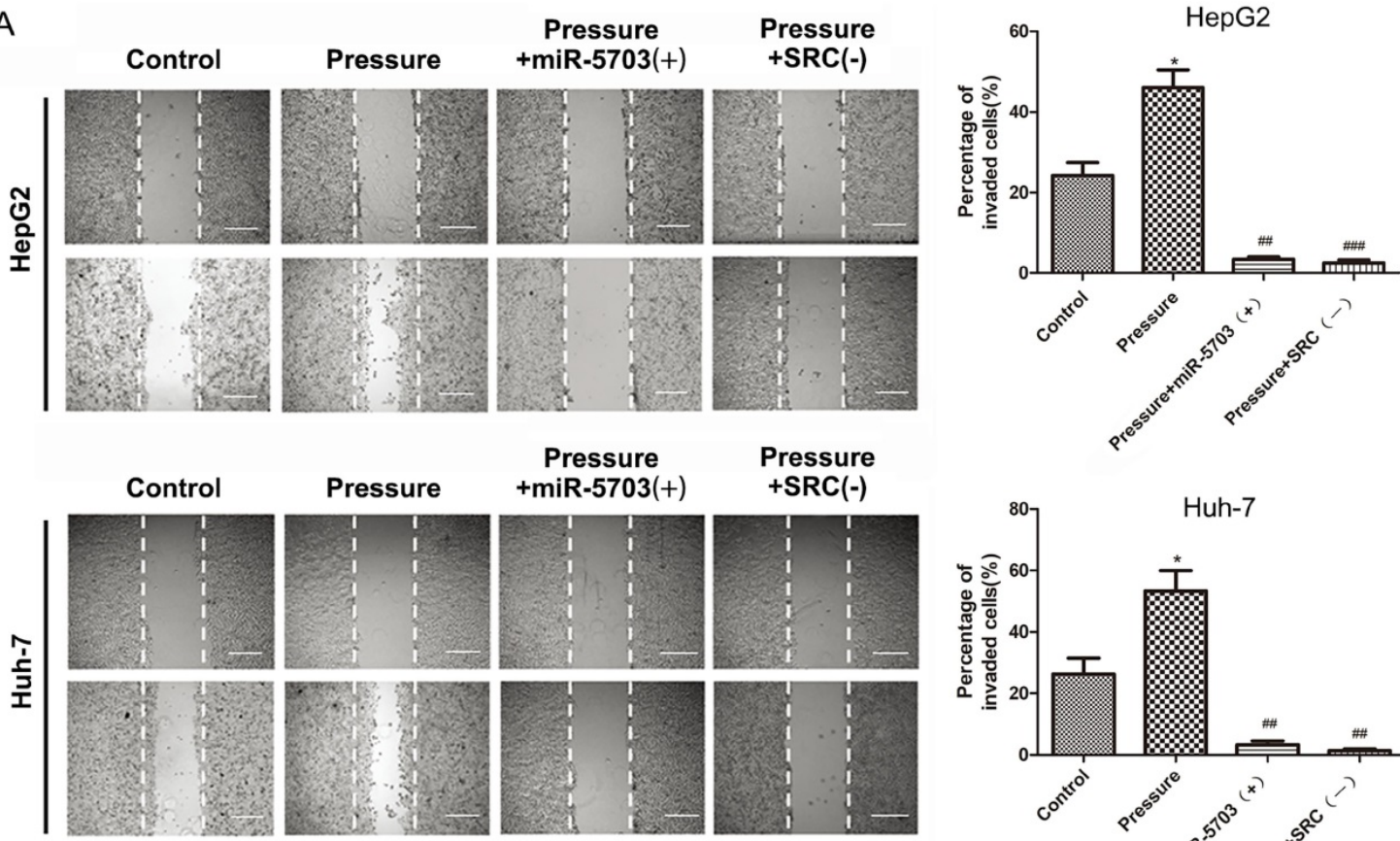

Pressure
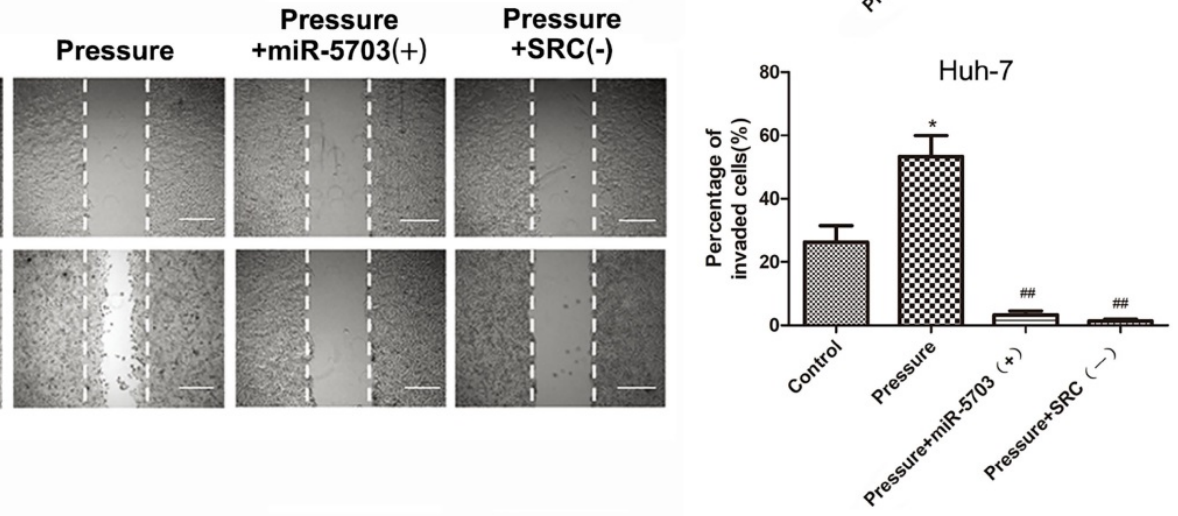

B
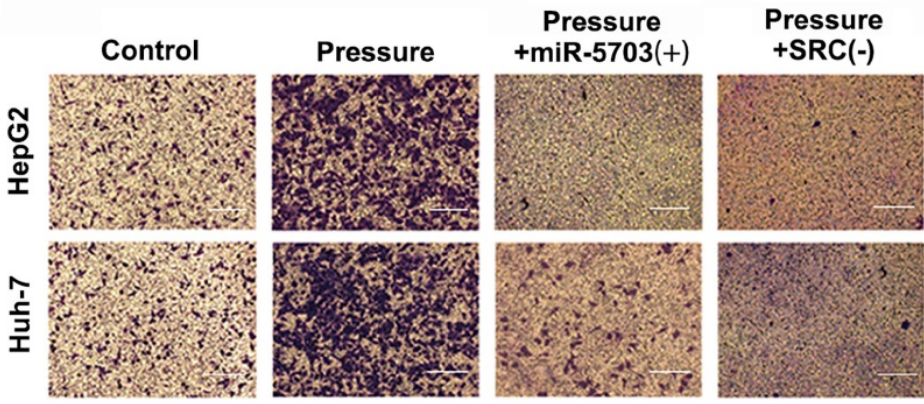

C
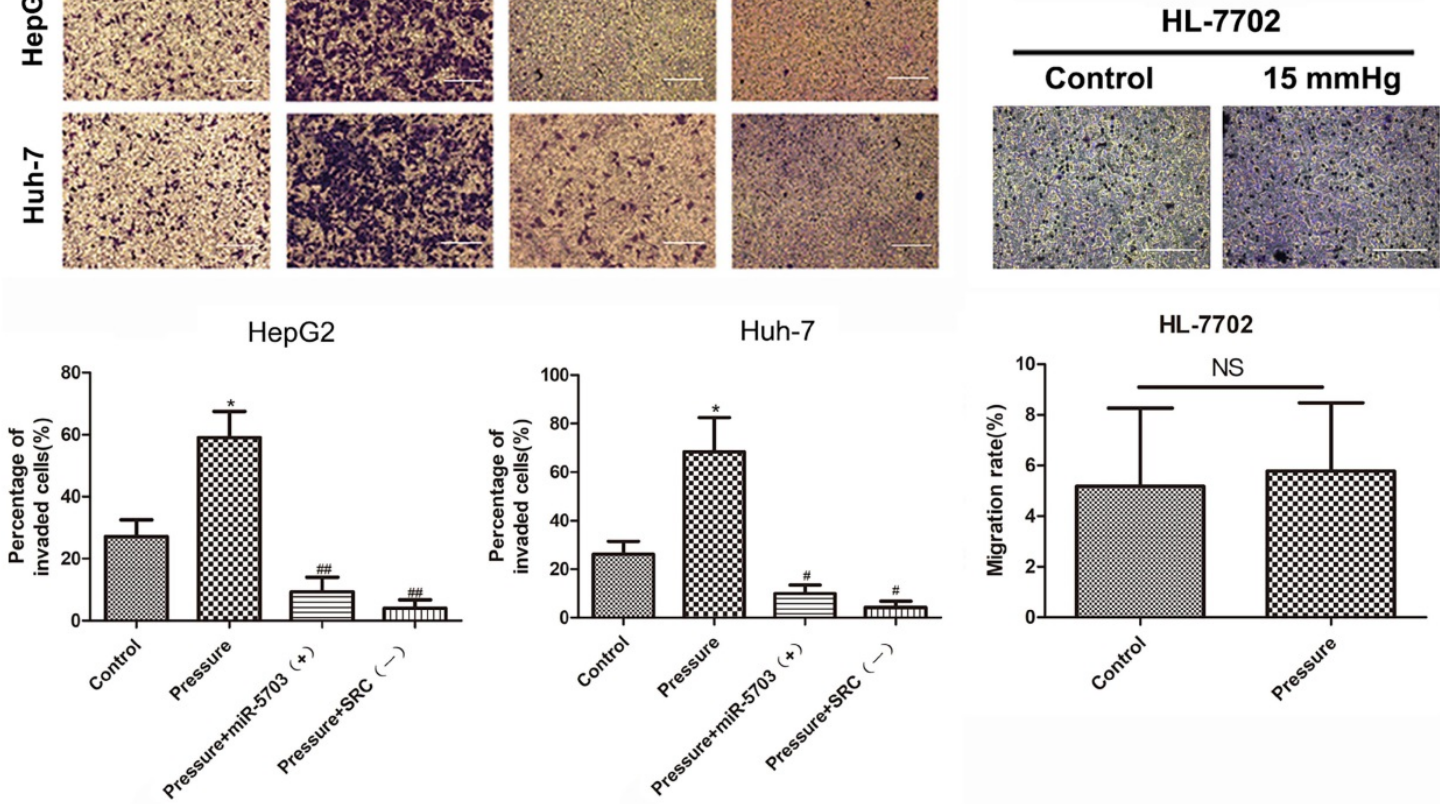

Figure 6. Overexpression of miRNA-5703 inhibited pressure-induced migration and invasion of hepatoma cells. (A) Overexpression of miRNA-5703 and SRC gene silenncing inhibited pressure-induced hepatoma cell migration which was assessed by cell scratch assay. The scale bars are $25 \mu \mathrm{m}$. (B) Overexpression of miRNA-5703 and SRC gene silencing inhibited pressure-induced hepatoma cell invasion which was assessed by transwell assay. The scale bars are $25 \mu \mathrm{m}$. (C) The transwell assay showed that there was no significant change in mobility of HL-7702 cells after pressure loading. Representative photographs were taken at a $\times 400$ magnification. The scale bars are $25 \mu \mathrm{m}$. NS indicates the

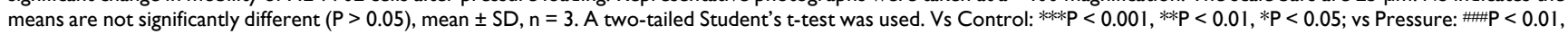
$\# \mathrm{P}<0.01$, \#P $<0.05$. 
A
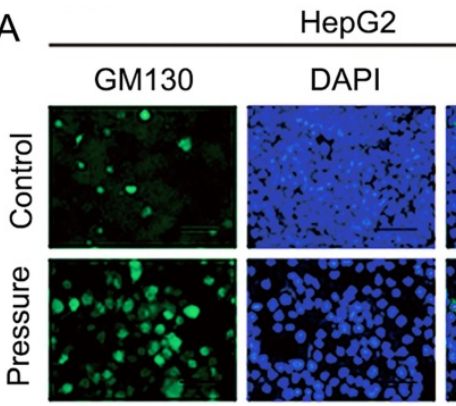

$\mathrm{MHCC} 97 \mathrm{H}$
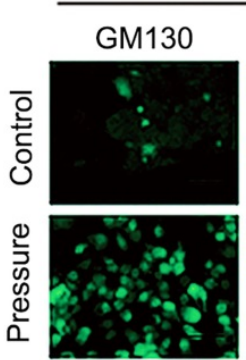

DAPI
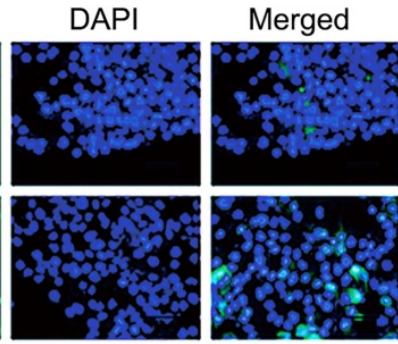

B

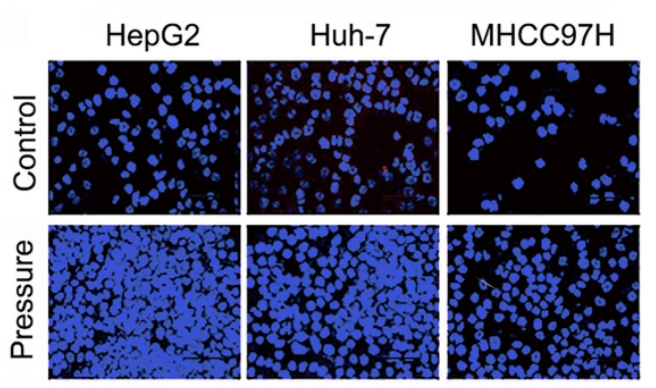

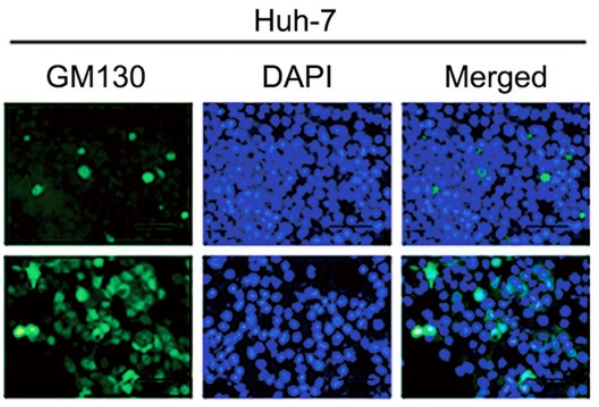
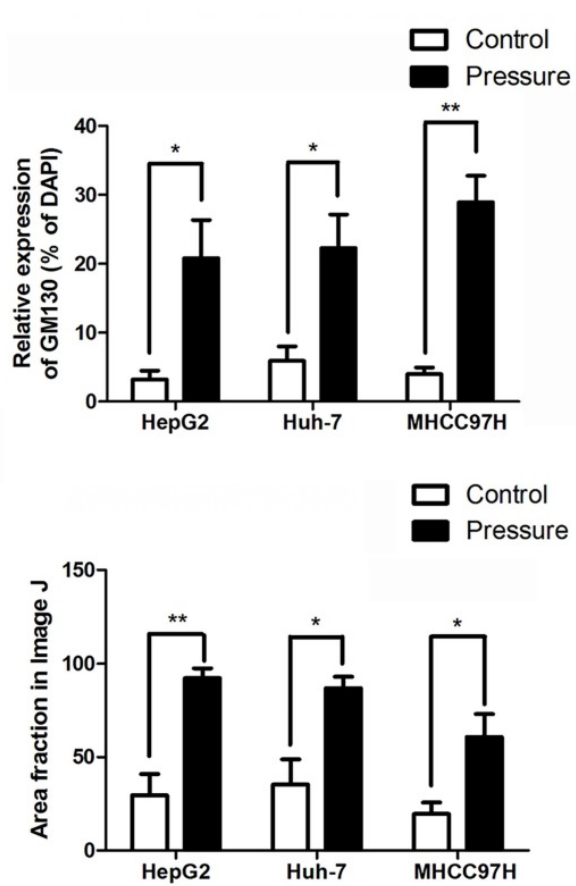

Figure 7. (A) The number of adherent HepG2, Huh-7, and MHCC97H cells on the matrix gel increased in cell adhesion assays. The scale bars are $50 \mu \mathrm{m}$. (B) GM130 expression in the indicated cells was analyzed by immunofluoresce. The scale bars are $50 \mu \mathrm{m}$. Mean $\pm \mathrm{SD}, \mathrm{n}=3$. A two-tailed Student's t-test was used vs Control: $* * \mathrm{P}<0.01$, *P $<0.05$

SRC was found to be the conjunct upstream protein of the top 3 enriched pathways (FA pathway, FOXO pathway, and PI3K pathway) using GO analysis of the 1,309 predicted target genes of miRNA-5703. Consistent with previous observations in human colon cancer cell lines and breast cancer cell lines [35-38], reducing SRC or inhibiting the FAK/PI3K axis blocked pressure-stimulated cell adhesion in liver cancer cell lines. The deformation of the liver cancer cell membrane caused a pressure-activated expression of SRC and pSRC (Y418), which could bind FA leading to the up-regulation of FAK and pFAK (Y397) and boosting the function of FA [39]. Therefore, pressure not only upregulated the expression of total SRC and FAK, but also promoted their phosphorylation, which maximised their activation effect.

Pressure-responsive miRNA-5703, which was identified by miRNA microarray, was predicted to target SRC. The expression of miRNA-5703 in liver cancer tissues of patients with PHTN was significantly lower than that in patients without
PHTN, while the expression of SRC had the opposite pattern. Increased translation of SRC in vivo activates downstream FAK and PI3K, which inactivate FOXOs by activating PDK1 to phosphorylate SGK3, suppressing FOXO1 which could inhibit P27kip1 and cyclin D1, and ultimately promotes cell proliferation. SRC activates cell motility associated proteins (vinculin, paxillin, and actin), which are important for the normal function of the cytoskeleton. The C-terminal region of paxillin contains four lim domain (LIM) domains, which anchor paxillin to FA [40]. The N-terminal region of paxillin is rich in protein-protein interaction sites, leading to its binding to a variety of proteins, including tyrosine kinases such as SRC and FAK [41], structural proteins such as vinculin and actopaxin, and actin regulators [42]. Our study found that physical distortion of the cytoskeleton transfers mechanical loads through actin- and microtubule-associated molecules to initiate intracellular signaling, and overexpression of miRNA-5703 may counteract this effect. 
A

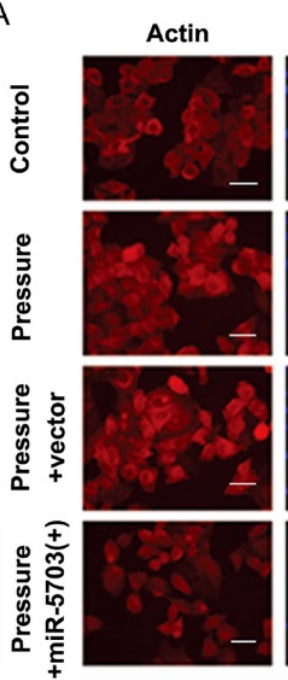

B
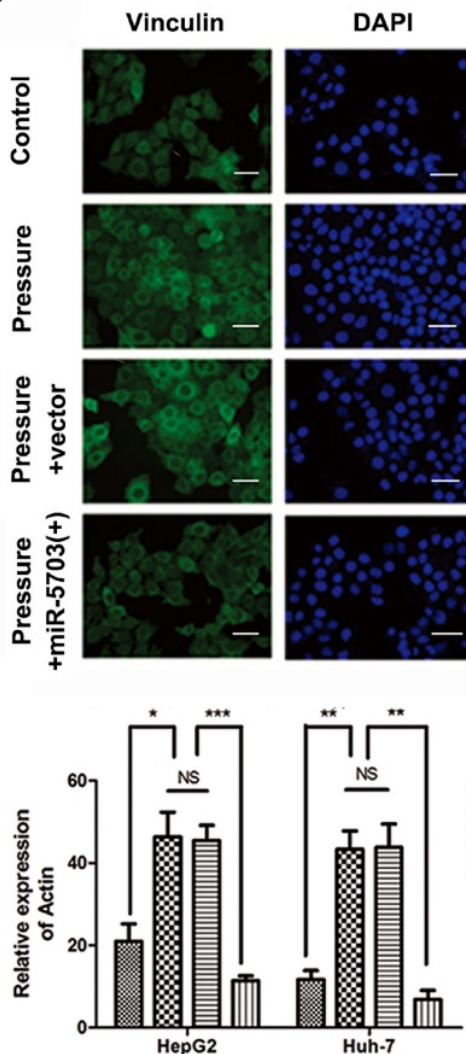
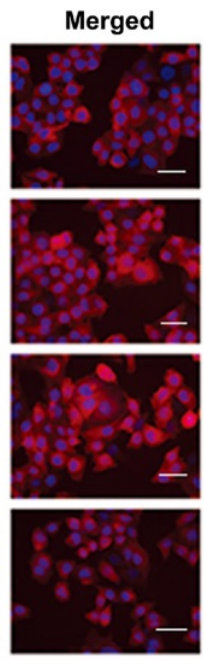

DAPI
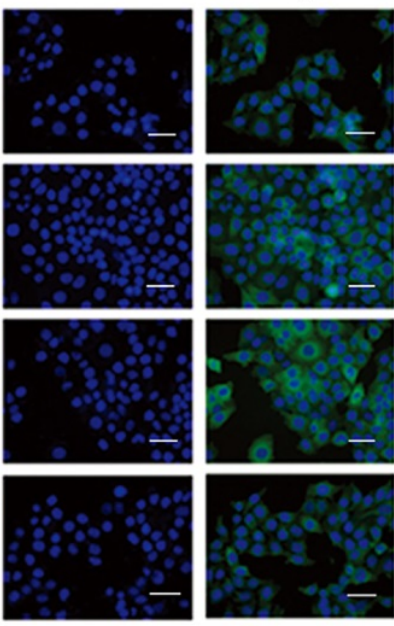
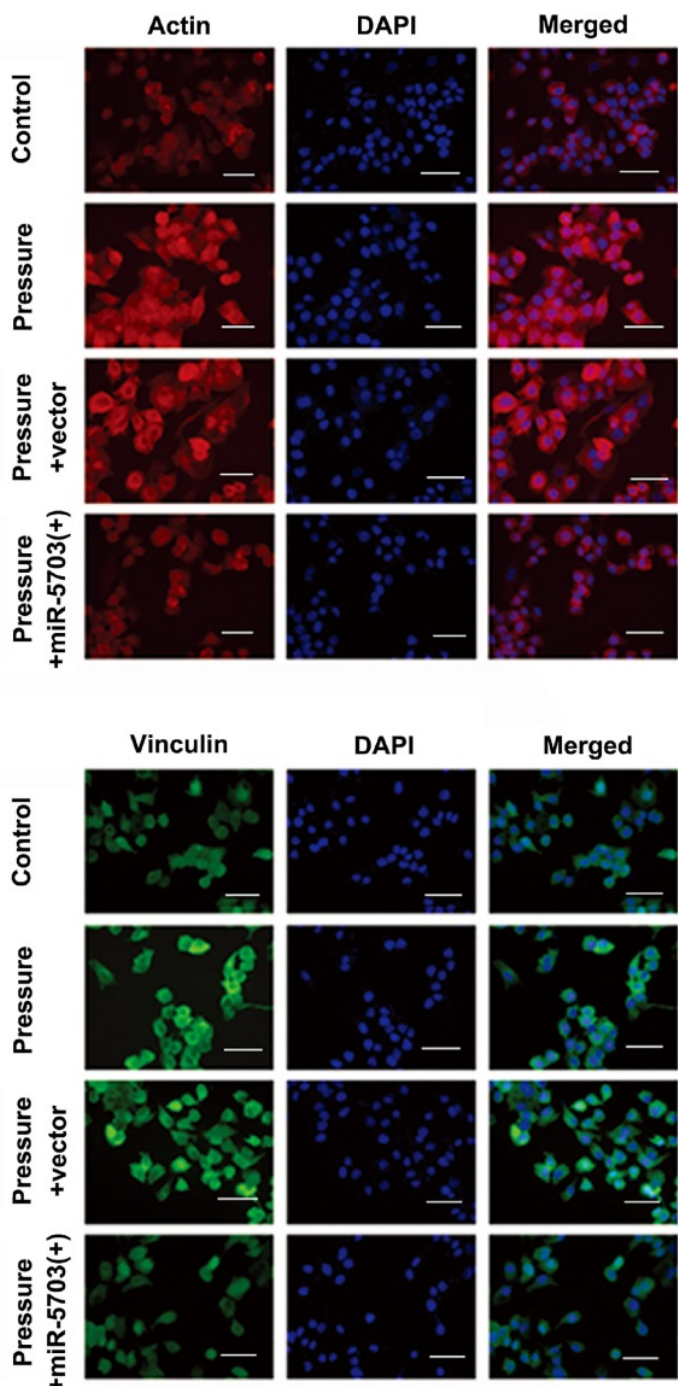

Control

$\infty$ Pressure

口 Pressure+vector

而 Pressure+miR-5703 (+)

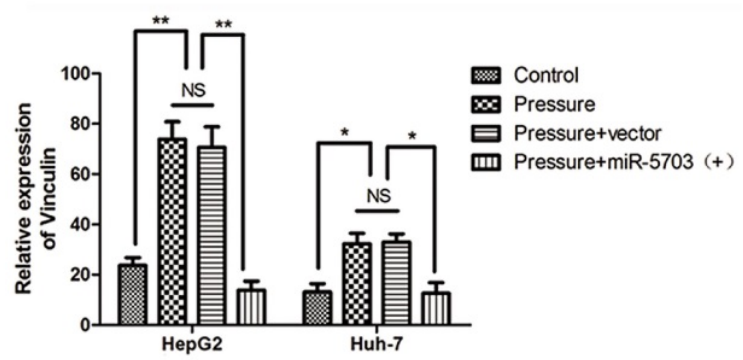

Figure 8. (A) Microfilaments of HepG2 and Huh-7 cells transfected with miRNA-5703 mimics were downregulated relative to that of cells transfected with the microRNA negative control (NC) as shown by staining with ghost pencil ring peptide. The quantification of the positive cells is shown on the right. The scale bars are $50 \mu \mathrm{m}$. (B) The expression of FA protein vinculin was inhibited by miRNA-5703 transfection as measured by immunofluorescence. The scale bars are $50 \mu \mathrm{m}$. NS indicates the means are not significantly different $(\mathrm{P}>0.05)$, mean $\pm S D, \mathrm{n}=3$. A two-tailed Student's t-test was used. $* * * \mathrm{P}<0.001, * * \mathrm{P}<0.01, * \mathrm{P}<0.05$.

Our pressure-induced subcutaneous tumourforming model of mice is different from that of liver cancer in the context of PHTN in cirrhosis. However, previous studies have suggested that it is feasible to implant cancer cells or stem cells loaded with pressure [43] or shear stress $[44,45]$ in vitro into nude mice and observe tumour formation in vivo and detect the expression of related proteins. Based on previous studies, we used 3D cell culture technology to mix cells into biogels to achieve a better simulation of the tumour mechanical microenvironment in vivo. Tumour size increased normally after implantation, and the protein expression in each group was significantly different.

Our study has some limitations. Although the role of pressure in promoting the migration and invasion of hepatoma cells has been fully confirmed in vitro, we only detected the expression of NM23 in 
subcutaneous tumours in vivo. In situ tumourigenesis in nude mice is necessary to further explore the effect of pressure on liver cancer metastasis, and further studies are needed. In addition, whether the cancer-promoting effect of pressure is related to membrane channel proteins is still unknown. Our previous microarray results confirmed that the mRNA levels of integrin subunits (av, a3, a6, a11, $\beta 4$, $\beta 6$, and $\beta 7$ ) was upregulated in pressurised hepatoma cells (GEO database: GSE120194) [14]. Integrins have been studied extensively in the mechanical signalling of cancer cells and cancer-associated fibroblasts, but not in liver cancer. In addition, the iron channel protein PIEZO2 and its target protein NOTCH1/2 were upregulated (GEO database: GSE120194) [14] PIEZO is a mechanically sensitive channel protein that has recently been implicated in the development and progression of various cancers [46]. The function of these membrane proteins and whether pressure-responsive miRNAs act on them requires further study.

A

\begin{tabular}{|l|c|c|c|c|c|c|c|c|}
\hline & $0 \mathrm{mmHg}$ & \multicolumn{7}{|c|}{$15 \mathrm{mmHg}$} \\
\hline DMSO & - & - & + & + & + & + & + & + \\
\hline Herbimycin A & - & - & - & + & - & - & - & - \\
\hline GSK225698 & - & - & - & - & + & - & - & - \\
\hline LY294002 & - & - & - & - & - & + & - & - \\
\hline PH-427 & - & - & - & - & - & - & + & - \\
\hline GSK650394 & - & - & - & - & - & - & - & + \\
\hline
\end{tabular}

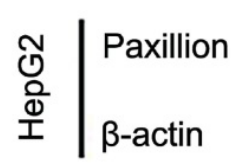

\begin{tabular}{l|l} 
곧․ & Paxillion \\
고 & \\
& $\beta$-actin
\end{tabular}

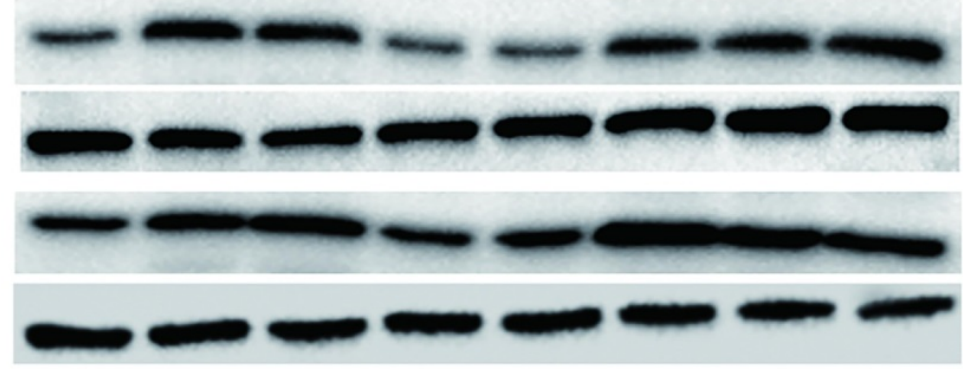

HepG2

Huh-7
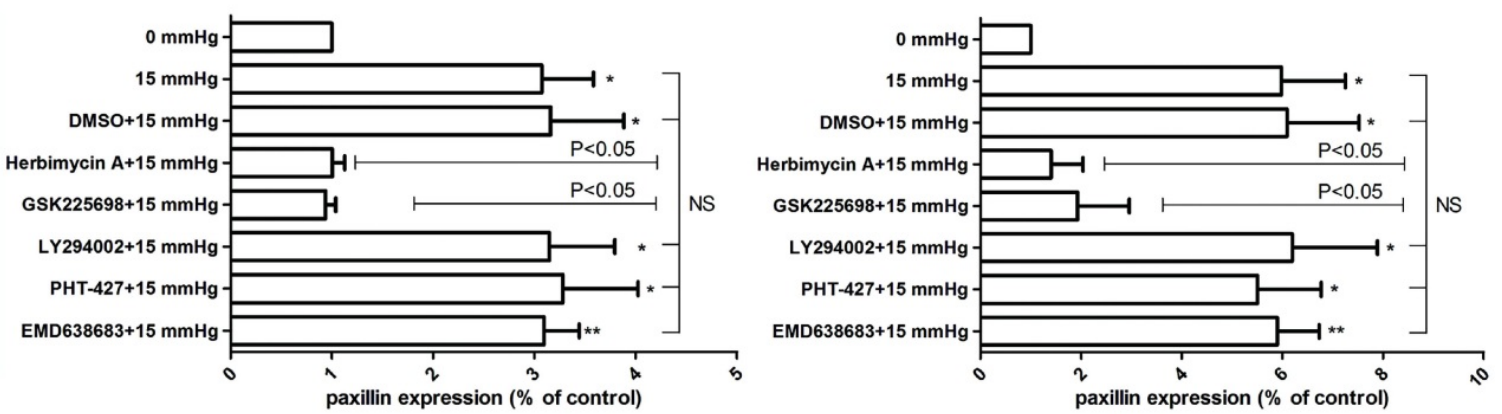

B

\begin{tabular}{|l|c|c|c|c|}
\hline Pressure & + & + & + & + \\
\hline MiR-5703 & NC & NC & + & + \\
\hline SRC & NC' & - & NC' & - \\
\hline
\end{tabular}

\begin{tabular}{l|l} 
তু & Paxillion \\
ํํํ & \\
I & $\beta$-actin
\end{tabular}

\begin{tabular}{l|l}
$\hat{1}$ & Paxillion \\
⿳亠口冋 & \\
I. & $\beta$-actin
\end{tabular}

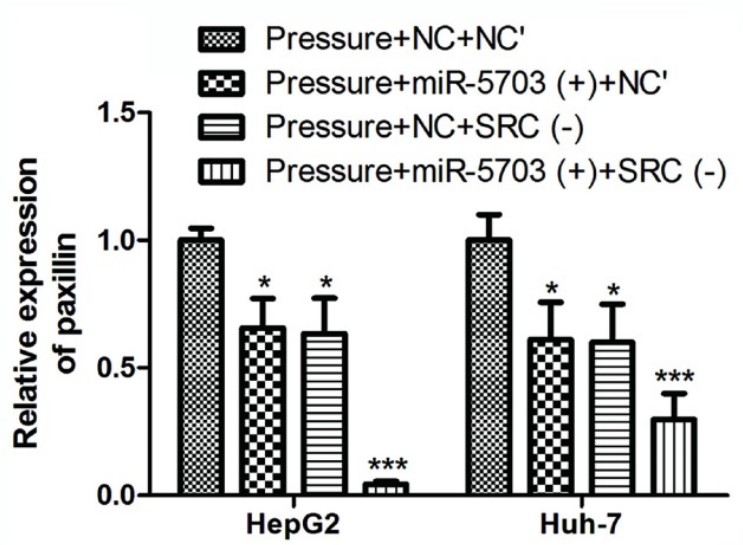

Figure 9. Overexpression of miRNA-5703 inhibited pressure-induced cell proliferation via the SRC-paxillin pathway. (A) Overexpression of miRNA-5703 and SRC gene silencing inhibited the expression of paxillin. (B) Herbimycin A and GSK2256098 inhibited paxillin expression while LY294002, PHT-427 and EMD638683 did not. 3 -actin was used as a loading control. Mean $\pm S D, n=3$. A two-tailed Student's t-test was used. $* * * P<0.001, * P<0.05$. 

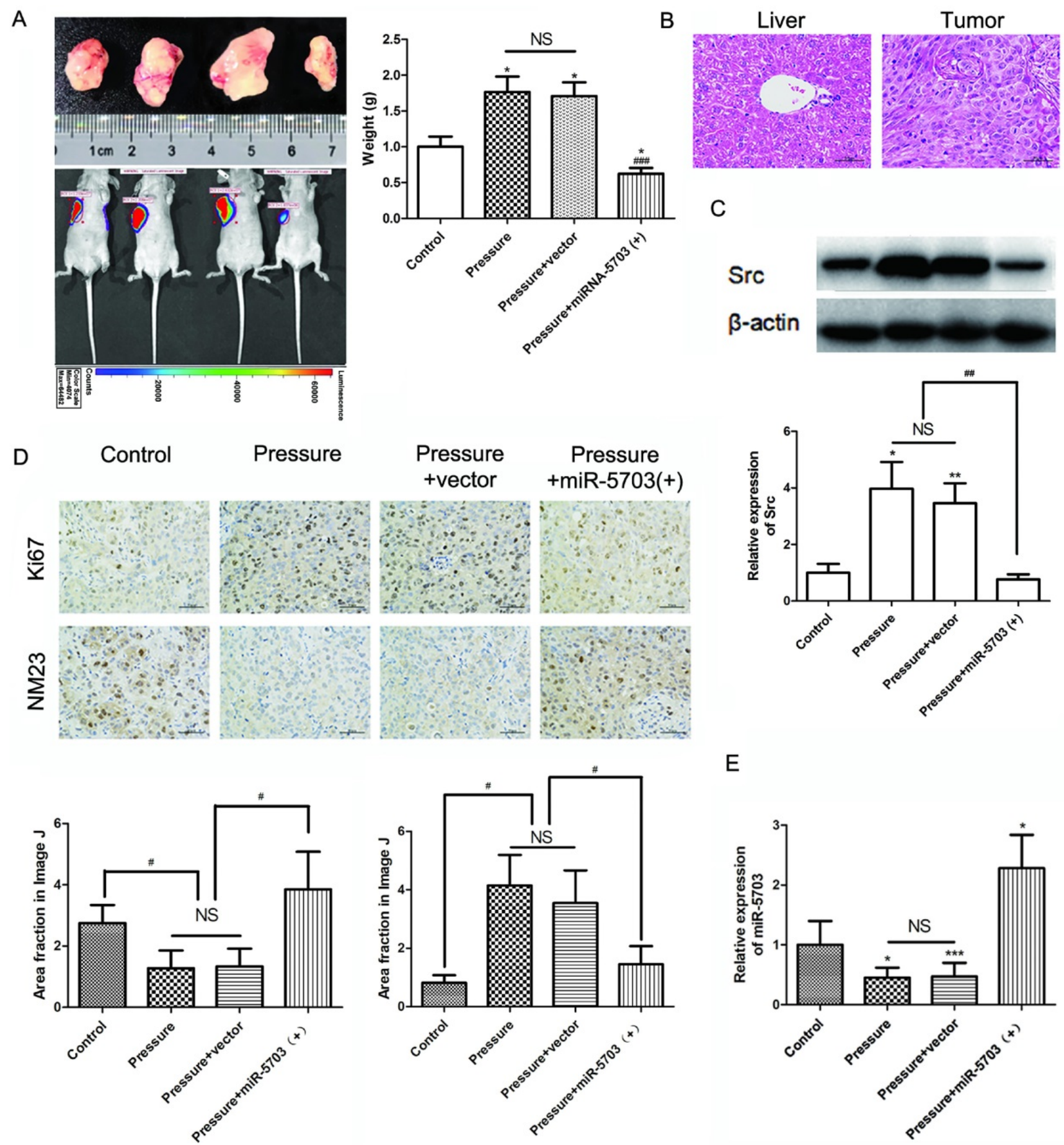

$\mathrm{E}$

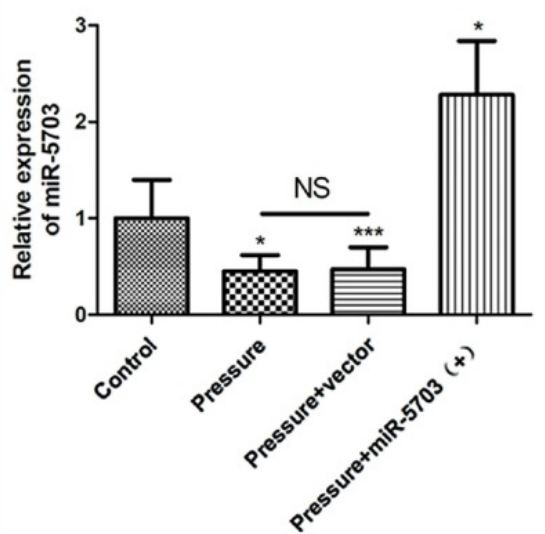

Figure 10. The effect of pressure on the growth and metastasis of liver cancer was verified in nude mice. (A) Overexpression of miRNA-5703 inhibited the pressure-induced tumour growth in subcutaneous $\mathrm{MHCC} 97 \mathrm{H}$ implanted nude mice. The nude mice were dissected and the subcutaneous tumours were taken out. The weight of the tumours under the four conditions were measured. (B) HE staining of normal liver tissues and tumour tissues from subcutaneous MHCC $97 \mathrm{H}$ implanted nude mice. The scale bars are 50 $\mu \mathrm{m}$. (C) The expression of SRC in tissues from nude mice was detected by western blotting, and $\beta$-actin was used as a loading control. (D) Immunohistochemical assays showed that overexpression of miRNA-5703 inhibited the expression of Ki67 and upregulated the suppression activity of NM23 in subcutaneous tumours in nude mice. Representative photographs were taken at $\times 400$ magnification. The scale bars are $25 \mu \mathrm{m}$. (E) The expression of miRNA-5703 in tumours under the four different conditions was detected by RT-qPCR. NS indicates the means are not significantly different $(\mathrm{P}>0.05)$, mean $\pm \mathrm{SD}, \mathrm{n}=3$. A two-tailed Student's t-test was used. Vs Control: ***P $<0.001$, **P $<0.01, * \mathrm{P}<$ 0.05; vs Pressure: $1 \mathrm{P}<0.01$, \#P $<0.01$, \#P $<0.05$. 


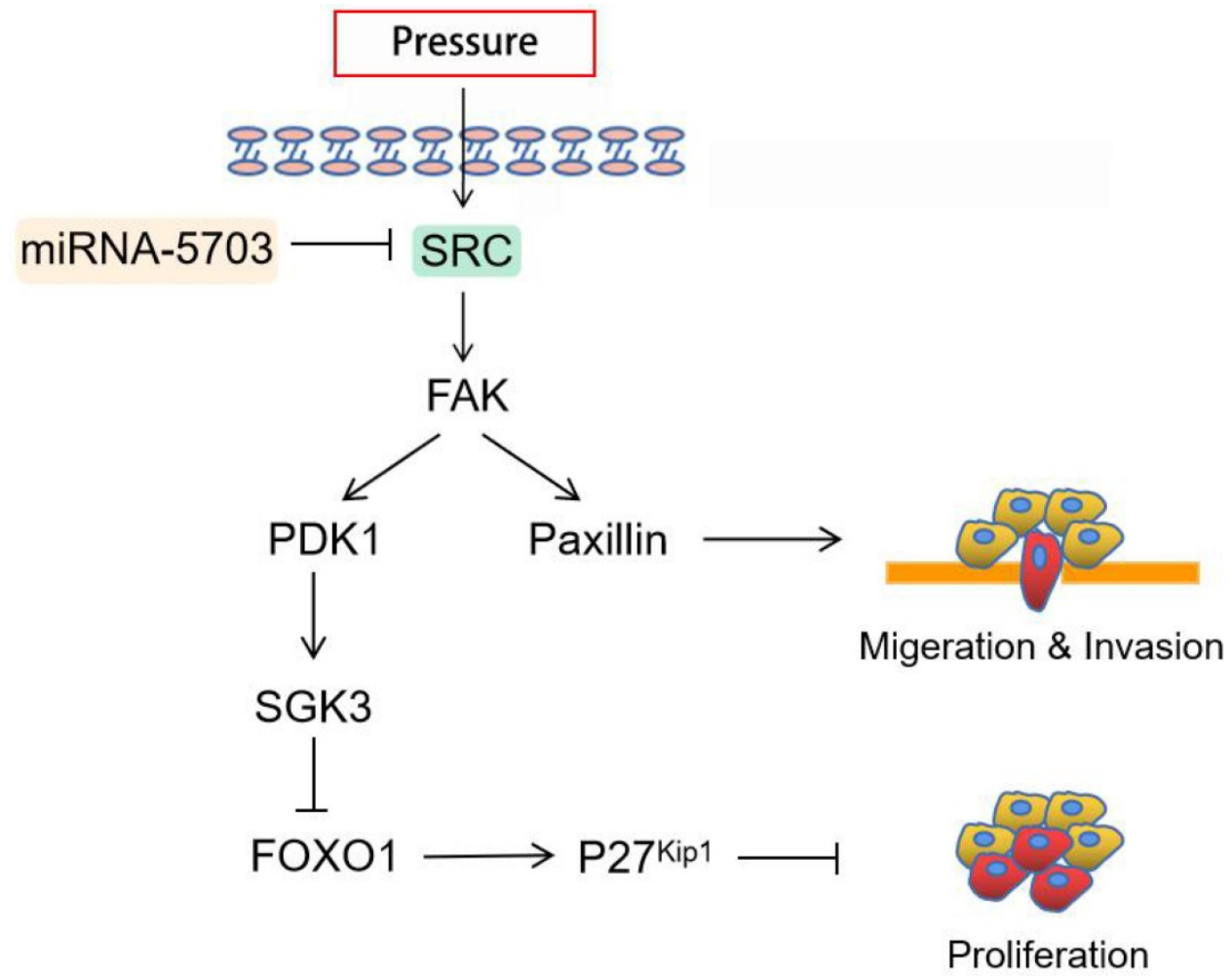

Figure 11. Schematic diagram summarizing how pressure-responsive miRNA-5703 promotes the growth and metastasis of liver cancer by inhibiting SRC expression.

\section{Abbreviations}

BCLC: Barcelona Clinic Liver Cancer; BSA: bovine serum albumin; CCK-8: Cell Counting Kit-8; CDKN1B, P27Kip1: Cyclin dependent kinase inhibitor 1B; 2D: 2-dimensional; 3D: 3-dimensional; FOXO1: Forkhead box O1; FAK: Focal adhesion kinase; FA: Focal Adhesion; GAPDH: Glyceraldehyde 3-phosphate dehydrogenase; HE: Hematoxylin-eosin; LIM: Lim domain; PBS: phosphate-buffered saline; PI3K, PIK3R1: Phosphatidylinositol 3-kinase; PDPK1, PDK1: Phosphoinositide dependent protein kinase 1; PHTN: Portal hypertension; PTK2: Protein tyrosine kinase-2; RT-qPCR: Quantitative reverse transcription polymerase chain reaction; SD: Standard deviation; SGK3: Serum/glucocorticoid regulated kinase-3; SRC: Sarcoma gene; TME: Tumour microenvironment.

\section{Supplementary Material}

Supplementary figures.

https://www.jcancer.org/v13p0325s1.pdf

\section{Acknowledgments}

This work was supported by funding from the National Natural Science Foundation of China (No. 11472300). In addition, we thank the National Natural Science Foundation of China (No. 81300345) and the international exchange grant (ref. IE151106) from The Royal Society of the UK.

\section{Competing Interests}

The authors have declared that no competing interest exists.

\section{References}

1. Ferlay J, Colombet M, Soerjomataram I, Mathers C, Parkin DM, Piñeros M, et al. Estimating the global cancer incidence and mortality in 2018: GLOBOCAN sources and methods. Int J Cancer. 2019; 144: 1941-53.

2. Bray F, Ferlay J, Soerjomataram I, Siegel RL, Torre LA, Jemal A. Global cancer statistics 2018: GLOBOCAN estimates of incidence and mortality worldwide for 36 cancers in 185 countries. CA Cancer J Clin. 2018; 68: 394-424.

3. Kudo M. Scientific Rationale for Combined Immunotherapy with PD-1/PD-L1 Antibodies and VEGF Inhibitors in Advanced Hepatocellular Carcinoma. Cancers (Basel). 2020; 12: 1089

4. Kole C, Charalampakis N, Tsakatikas S, Vailas M, Moris D, Gkotsis E, et al. Immunotherapy for Hepatocellular Carcinoma: A 2021 Update. Cancers (Basel). 2020; 12: 2859

5. Aragon-Sanabria V, Kim GB, Dong C. From Cancer Immunoediting to New Strategies in Cancer Immunotherapy: The Roles of Immune Cells and Mechanics in Oncology. Adv Exp Med Biol. 2018; 1092: 113-38.

6. Faitot F, Allard MA, Pittau G, Ciacio O, Adam R, Castaing D, et al. Impact of clinically evident portal hypertension on the course of hepatocellular carcinoma in patients listed for liver transplantation. Hepatology. 2015; 62: 179-87.

7. Marasco G, Colecchia A, Colli A, Ravaioli F, Casazza G, Bacchi Reggiani ML et al. Role of liver and spleen stiffness in predicting the recurrence of hepatocellular carcinoma after resection. J Hepatol. 2019; 70: 440-8.

8. Marasco G, Colecchia A, Silva G, Rossini B, Eusebi LH, Ravaioli F, et al. Non-invasive tests for the prediction of primary hepatocellular carcinoma. World J Gastroenterol. 2020; 26: 3326-43.

9. Xu XF, Xing H, Han J, Li ZL, Lau WY, Zhou YH, et al. Risk Factors, Patterns, and Outcomes of Late Recurrence After Liver Resection for Hepatocellular Carcinoma: A Multicenter Study From China. JAMA Surg. 2019; 154: 209-17.

10. Kim R, Jeong WK, Kang TW, Song KD, Lee MW, Ahn SH, et al. Intrahepatic distant recurrence after radiofrequency ablation of hepatocellular carcinoma: relationship with portal hypertension. Acta Radiol. 2019; 60: 1609-18.

11. Hilscher MB, Sehrawat T, Arab JP, Zeng Z, Gao J, Liu M, et al. Mechanical Stretch Increases Expression of CXCL1 in Liver Sinusoidal Endothelial Cells to Recruit Neutrophils, Generate Sinusoidal Microthombi, and Promote Portal Hypertension. Gastroenterology. 2019; 157: 193-209.e9. 
12. Luo X, Shen S, Yi S, Hu J, Sun Y, Gao K, et al. Screening of differentially expressed miRNAs in tensile strain-treated HepG2 cells by miRNA microarray analysis. Mol Med Rep. 2020; 21: 2415-26.

13. Qi F, Hu JF, Liu BH, Wu CQ, Yu HY, Yao DK, et al. MiR-9a-5p regulates proliferation and migration of hepatic stellate cells under pressure through inhibition of Sirt1. World J Gastroenterol. 2015; 21: 9900-15.

14. Shen S, Luo X, Gao K, Sun Y, Yao D, Zhu L. Identification and integrative analysis of microRNAs and mRNAs involved in proliferation and invasion of pressure-treated human liver cancer cell lines. Mol Med Rep. 2019; 20: 375-87.

15. Kalli M, Stylianopoulos T. Defining the Role of Solid Stress and Matrix Stiffness in Cancer Cell Proliferation and Metastasis. Front Oncol. 2018; 8: 55.

16. Chaudhuri PK, Low BC, Lim CT. Mechanobiology of Tumor Growth. Chem Rev. 2018; 118: 6499-515.

17. Zeng B, Devadoss D, Wang S, Vomhof-DeKrey EE, Kuhn LA, Basson MD. Inhibition of pressure-activated cancer cell adhesion by FAK-derived peptides. Oncotarget. 2017; 8: 98051-67.

18. Basson MD, Zeng B, Downey C, Sirivelu MP, Tepe JJ. Increased extracellular pressure stimulates tumor proliferation by a mechanosensitive calcium channel and PKC- $\beta$. Mol Oncol. 2015; 9: 513-26.

19. Sheen MR, Fields JL, Northan B, Lacoste J, Ang LH, Fiering S. Replication Study: Biomechanical remodeling of the microenvironment by stromal caveolin-1 favors tumor invasion and metastasis. Elife. 2019; 8: e45120

20. Fernández-Sánchez ME, Barbier $S$, Whitehead J, Béalle G, Michel A, Latorre-Ossa $\mathrm{H}$, et al. Mechanical induction of the tumorigenic $\beta$-catenin pathway by tumour growth pressure. Nature. 2015; 523: 92-5.

21. Pasta S, Agnese V, Gallo A, Cosentino F, Di Giuseppe M, Gentile G, et al. Shear Stress and Aortic Strain Associations With Biomarkers of Ascending Thoracic Aortic Aneurysm. Ann Thorac Surg. 2020; 110: 1595-604.

22. Cazzanelli P, Wuertz-Kozak K. MicroRNAs in Intervertebral Disc Degeneration, Apoptosis, Inflammation, and Mechanobiology. Int J Mol Sci. 2020; 21: 3601

23. Stadnik PS, Gilbert SJ, Tarn J, Charlton S, Skelton AJ, Barter MJ, et al. Regulation of microRNA-221, -222, -21 and -27 in articular cartilage subjected to abnormal compressive forces. J Physiol. 2021; 599: 143-55.

24. Rice DC, Dobrian AD, Schriver SD, Prewitt RL. Src autophosphorylation is an early event in pressure-mediated signaling pathways in isolated resistance arteries. Hypertension. 2002; 39: 502-7.

25. Basnet R, Gong GQ, Li C, Wang MW. Serum and glucocorticoid inducible protein kinases (SGKs): a potential target for cancer intervention. Acta Pharm Sin B. 2018; 8: 767-71.

26. Polyak K, Lee MH, Erdjument-Bromage H, Koff A, Roberts JM, Tempst P, et al. Cloning of p27Kip1, a cyclin-dependent kinase inhibitor and a potential mediator of extracellular antimitogenic signals. Cell. 1994; 78: 59-66.

27. Bellis SL, Miller JT, Turner CE. Characterization of tyrosine phosphorylation of paxillin in vitro by focal adhesion kinase. J Biol Chem. 1995; 270: 17437-41.

28. Schaller MD, Schaefer EM. Multiple stimuli induce tyrosine phosphorylation of the Crk-binding sites of paxillin. Biochem J. 2001; 360: 57-66.

29. Shen J, Sun Y, Shen S, Luo X, Chen J, Zhu L. Pressure suppresses hepatocellular glycogen synthesis through activating the p53/Pten pathway. Mol Med Rep. 2019; 19: 5105-14

30. Felsen D, Diaz BJ, Chen J, Gonzalez J, Kristensen M, Bohn AB, et al. Pressure and stretch differentially affect proliferation of renal proximal tubular cells. Physiol Rep. 2017; 5: e13346

31. Livak KJ, Schmittgen TD. Analysis of relative gene expression data using real-time quantitative PCR and the 2(-Delta Delta $\mathrm{C}(\mathrm{T})$ ) Method. Methods. 2001; 25: 402-8.

32. Baschieri F, Uetz-von Allmen E, Legler DF, Farhan H. Loss of GM130 in breast cancer cells and its effects on cell migration, invasion and polarity. Cell Cycle. 2015; 14: 1139-47.

33. Jain P, Wang M. Mantle cell lymphoma: 2019 update on the diagnosis, pathogenesis, prognostication, and management. Am J Hematol. 2019; 94: 710-25.

34. Liu W, Vivian CJ, Brinker AE, Hampton KR, Lianidou E, Welch DR. Microenvironmental Influences on Metastasis Suppressor Expression and Function during a Metastatic Cell's Journey. Cancer Microenviron. 2014; 7: $117-31$.

35. Thamilselvan V, Craig DH, Basson MD. FAK association with multiple signal proteins mediates pressure-induced colon cancer cell adhesion via a Src-dependent PI3K/Akt pathway. FASEB J. 2007; 21: 1730-41.

36. Wang S, Basson MD. Akt directly regulates focal adhesion kinase through association and serine phosphorylation: implication for pressure-induced colon cancer metastasis. Am J Physiol Cell Physiol. 2011; 300: C657-70.

37. Zeng B, Devadoss D, Wang S, Vomhof-DeKrey EE, Kuhn LA, Basson MD. Inhibition of pressure-activated cancer cell adhesion by FAK-derived peptides. Oncotarget. 2017; 8: 98051-67.

38. Downey $\mathrm{C}$, Alwan $\mathrm{K}$, Thamilselvan $\mathrm{V}$, Zhang $\mathrm{L}$, Jiang $\mathrm{Y}$, Rishi AK, et al Pressure stimulates breast cancer cell adhesion independently of cell cycle and apoptosis regulatory protein (CARP)-1 regulation of focal adhesion kinase. Am J Surg. 2006; 192: 631-5.

39. Heerkens EH, Quinn L, Withers SB, Heagerty AM. $\beta$ Integrins mediate FAK Y397 autophosphorylation of resistance arteries during eutrophic inward remodeling in hypertension. J Vasc Res. 2014; 51: 305-14.

40. Ripamonti M, Liaudet N, Azizi L, Bouvard D, Hytönen VP, Wehrle-Haller B. Structural and functional analysis of LIM domain-dependent recruitment of paxillin to av $\beta 3$ integrin-positive focal adhesions. Commun Biol. 2021; 4: 380.
41. Vashum $Y$, Premsingh $R$, Kottaiswamy A, Soma $M$, Padmanaban A, Kalaiselvan P, et al. Inhibitory effect of cathepsin K inhibitor (ODN-MK-0822) on invasion, migration and adhesion of human breast cancer cells in vitro. Mol Biol Rep. 2021; 48: 105-16.

42. Turner CE. Paxillin interactions. J Cell Sci. 2000; 113 Pt 23: 4139-40.

43. Craig DH, Owen CR, Conway WC, Walsh MF, Downey C, Basson MD. Colchicine inhibits pressure-induced tumor cell implantation within surgical wounds and enhances tumor-free survival in mice. J Clin Invest. 2008; 118: $3170-80$

44. Sun J, Luo Q, Liu L, Song G. Low-level shear stress induces differentiation of liver cancer stem cells via the Wnt/ $\beta$-catenin signalling pathway. Exp Cell Res. 2019; 375: 90-6.

45. Alvarado-Estrada K, Marenco-Hillembrand L, Maharjan S, Mainardi VL, Zhang YS, Zarco N, et al. Circulatory shear stress induces molecular changes and side population enrichment in primary tumor-derived lung cancer cells with higher metastatic potential. Sci Rep. 2021; 11: 2800.

46. Pethő Z, Najder K, Bulk E, Schwab A. Mechanosensitive ion channels push cancer progression. Cell Calcium. 2019; 80: 79-90. 